\title{
Investigation of Crystal Structure, Electrical and Magnetic Properties of Spinel Mn-Cd Ferrite Nanoparticles
}

M. H. Badr

Delta Technological University

M. H. Nasr

Delta Technological University

M. M. Elkholy

Delta Technological University

L. M. S. El-Deen

Delta Technological University

Gamal M. Turky

National Research Centre

M. Moustafa

American University in Cairo

\section{A. S. Abouhaswa ( $\nabla$ aliabohaswa@hotmail.com )}

Delta Technological University

\section{A. A. EL Hamalawy}

Delta Technological University

\section{Research Article}

Keywords: Manganese Ferrites, auto combustion, X-ray diffraction, Infrared spectroscopy, Elastic properties, Magnetic properties, Dielectric properties, Ac-conductivity

Posted Date: August 12th, 2021

DOl: https://doi.org/10.21203/rs.3.rs-799645/v1

License: (c) (i) This work is licensed under a Creative Commons Attribution 4.0 International License. Read Full License 


\title{
Investigation of crystal structure, electrical and magnetic properties of Spinel Mn-Cd ferrite nanoparticles
}

\author{
M. H. Badr ${ }^{1}$, M. H. Nasr ${ }^{1,2}$, M. M. Elkholy ${ }^{1}$, L. M. S. El-Deen ${ }^{1}$, Gamal M.

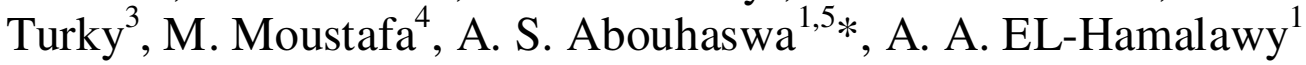 \\ ${ }^{1}$ Department of Physics, Faculty of Science, Menoufia University, Shebin El-Koom 32511, \\ Egypt \\ ${ }^{2}$ Department of Renewable Energy, Faculty of Technological Industry and Energy, Delta \\ Technological University, Quesna Egypt \\ ${ }^{3}$ Department of Microwave Physics \& Dielectrics, National Research Centre, Giza 12622, Egypt \\ ${ }^{4}$ Department of physics, School of science and engineering, American University in Cairo, Egypt \\ ${ }^{5}$ Institute of Natural Science and Mathematics, Ural Federal University, Ekaterinburg 620002, \\ Russia
}

Corresponding author: A.S. Abouhaswa E-mail: aliabohaswa@hotmail.com 


\section{Abstract:}

$\mathrm{Fe}_{2} \mathrm{Cd}_{1-\mathrm{x}} \mathrm{Mn}_{\mathrm{x}} \mathrm{O}_{4}(\mathrm{x}=0,0.25,0.5,0.75,1)$ spinel ferrite nanoparticle samples were synthesized using a flash auto-combustion technique and analyzed using X-ray diffraction (XRD), scanning electron microscopy (SEM), and Fourier-transform infrared spectroscopy (FTIR). The inspection of dielectric and magnetic properties of the prepared ferrites was carried out by using broadband dielectric spectroscopy (BDS) and vibration sample magnetometer (VSM) measurements, respectively. Xray diffraction analysis verified the formation of the main cubic phase with space group $\mathrm{Fd} 3 \mathrm{~m}$ and a decrease in lattice constants with the increase in Mn-content. FTIR study revealed the two characteristic absorption bands of spinel ferrites and their dependence on Mn-content was investigated and explained. Elastic moduli such as Longitudinal, transverse and mean elastic wave velocities $\left(V_{l}, V_{t} V_{m}\right)$, bulk modulus $(B)$, rigidity modulus $(G)$, Young modulus $(E)$ and calculated Debye temperature $\left(\theta_{D}\right)$ have been studied and found to decrease with the increase in Mncontent. SEM analysis revealed nanoparticles agglomeration of uniform grains with increasing in the average grain size as Mn-content increased. The VSM measurements showed an increase in saturation magnetization $\left(M_{s}\right)$ accompanied by a decrease in coercivity $\left(H_{\mathrm{c}}\right)$ as Mn-content increased. Dielectric investigations showed very high values of permittivity and dielectric loss at lower frequencies reflecting the combination of exchange of electrons between ferrous and ferric ions and ions' transport. The ac-conductivity showed a plateau that yields the dcconductivity $\left(\sigma_{\mathrm{dc}}\right)$ at lower frequencies followed by a characteristic frequency $\left(v_{\mathrm{c}}\right)$ at which it tends out to follow a power law. The relation between these two parameters confirms the empirical BNN-relation.

\section{Keywords:}

Manganese Ferrites; auto combustion; X-ray diffraction; Infrared spectroscopy; Elastic properties; Magnetic properties; Dielectric properties; Ac-conductivity 


\section{Introduction}

In the last few years several researches are carried out on magnetic nanoparticles to increase the potential of applications in this field by improving their physical properties for several industrial and technological applications. Between these, soft ferromagnetic materials are commonly used in both DC and AC applications such as electromagnets, relays, transformers, motors, generators, inductors, antenna rods, microwave isolators, phase shifters and filters [1-3].

Nanosized magnetic particles have properties which are definitely unlike that of the relating bulk materials because of their reduced size and the consequent impact of magnetic interactions between particles. Spinel ferrite nanoparticles have the common formula $\mathrm{AFe}_{2} \mathrm{O}_{4}$ (A: divalent metal cation) where a face-centered cubic lattice is formed by oxygen ions and A ions located at tetrahedral and/or octahedral sublattice sites $[4,5]$. The unpaired electrons of transition metal cations positioned at tetrahedral and octahedral sites are responsible for magnetization in spinel ferrites due to variations in their spin magnetic momnets. The substituted cations may be linked into the lattice of the host ferrites which successively changes the whole distribution of the cations in the system [6].

The chemical composition and method of preparation can effectively control the cation distribution in the ferrites. Nano-ferrites are prepared by emplying several methods listed and reviewed by Ref. [7-12]. Among these methods is the citrate-gel auto-combustion method that was employed to synthesize the present work. This preparation technique has the advantage of not only producing nano-sized spinel ferrites with high-grade quality in terms of homogeneity and control of stoichiometry, but also simplicity related with preparation temperature and time.

Yadav et al. [13] reported that introducing $\mathrm{Mn}^{2+}$ in system of cobalt ferrite with a ratio of 0.3 increased the the value of saturation magnetization by $31.2 \%$. Mixed Cdferrite has significant technical applications as these ferrites are characterized by high resistivity, high permeability and low magnetic losses. Conjugation of various divalent metallic ions in chemical structure of ferrites might increase their distinctive features. 
The addition of cobalt ions to ferrites improved coercivity by increasing the magnetocrystalline anisotropy caused by the interaction of cobalt and iron ion's spins [14].

In the present work, spinel $\mathrm{Fe}_{2} \mathrm{Cd}_{1-\mathrm{x}} \mathrm{Mn}_{\mathrm{x}} \mathrm{O}_{4}$ ferrites with $\mathrm{x}=0,0.25,0.5,0.75,1$ were prepared by citrate-gel auto-combustion technique. The effect of $\mathrm{Mn}^{2+}$ ions substitution on the crystal structure, characteristic absorption bands, elastic properties and magnetic parameters were investigated. Moreover, the dielectric and electrical properties of all samples were studied over a broad range of frequencies ranging from $0.1 \mathrm{~Hz}$ to $20 \mathrm{MHz}$ at ambient temperature.

\section{Experimental techniques}

\subsection{Samples preparation}

Nano-sized $\mathrm{Fe}_{2} \mathrm{Cd}_{1-\mathrm{x}} \mathrm{Mn}_{\mathrm{x}} \mathrm{O}_{4}$ ferrites with $\mathrm{x}=0.00,0.25,0.50, .0 .75$ and 1.00 were synthesized by using a flash auto-combustion method as illustrated in Fig. 1. At room temperature, small amount of distilled water was used to dissolve stoichiometric concentrations of the listed nitrates as shown in Fig.1 and citric acid as a fuel. The resultant solution was mixed using magnetic stirrer at $70{ }^{\circ} \mathrm{C}$ to ensure homogeneity and the $\mathrm{pH}$ value was fine-tuned by using ammonia.. To evaporate residual water; the mixture was heated at about $95{ }^{\circ} \mathrm{C}$ under regular stirring. The obtained brown gel was spontaneously ignited at ambient air and resulted in the formation of gases and light brown ash powder. Using a mortar and pestle, the porous ash samples were crushed into fine powder and annealed at $300{ }^{\circ} \mathrm{C}$ for 6 hours. Then, these powders were subjected to a second cycle of grinding to be ready for various investigations.

\subsection{Samples characterization}

Powder X-ray diffraction (XRD) measurements were employed to study the structure and phase purity of the samples by using Bruker D8 Advance diffractometer with $\mathrm{Cu}$ $\mathrm{K}_{a}$ radiation. The obtained XRD patterns were examined by Rietveld method along with Fullprof software.The images for the analyzed samples were obtained with a scanning electron microscope (Quanta $250 \mathrm{FEG}$ ) attached to an EDX unit. Image $\mathrm{J}$ software was used to analyise the SEM images.. 
The infrared spectrometer Perkin-Elmer 1430, Germany, was used to perform FTIR spectra on all studied samples in the wavenumber range of $200-4000 \mathrm{~cm}^{-1}$. The vibrating sample magnetometer (VSM) was used to investigate magnetic hysteresis characteristics in magnetic fields with intensities up to $25 \mathrm{kOe}$ at room temperature.

Dielectric investigations of samples were performed using a Novocontrol high-resolution alpha analyzer in the frequency range $10^{-1}-10^{7} \mathrm{~Hz}$ at room temperature. The investigated samples with a thicknesses of 1-2 mm were sandwiched between two freshly polished brass electrodes with a top electrode diameter of $10 \mathrm{~mm}$ to form a parallel-plate capacitor cell. The complex permittivity $\left(\varepsilon^{*}=\varepsilon^{\prime}-\mathrm{i} \varepsilon^{\prime \prime}\right)$ was measured using a sinusoidal voltage with amplitude $1 \mathrm{~V}$ over a $10^{-1}-10^{7} \mathrm{~Hz}$ frequency range in all experiments. In the complex dielectric spectroscopy, the investigated composites can be characterized according to any of the complex parameters that are related to each other as expressed in the following Eqn. (1):

$$
\varepsilon^{*}(\omega)=\varepsilon^{\prime}(\omega)-i \varepsilon^{\prime \prime}(\omega)=\frac{1}{M^{*}}=\frac{\sigma^{*}}{i \omega \varepsilon_{o}}
$$

where, $M^{*}=M^{\prime}+i M^{\prime \prime}, \sigma^{*}=\sigma^{\prime}+\mathrm{i} \sigma^{\prime \prime}, \mathrm{i}=\sqrt{ } 1, \omega=2 \pi f$ is the angular frequency and $\varepsilon_{0}$ is the vacuum permittivity.

\section{Results and discussion}

\subsection{XRD analysis}

$\mathrm{X}$-ray diffraction (XRD) patterns of the prepared $\mathrm{Cd}_{1-\mathrm{x}} \mathrm{Mn}_{\mathrm{X}} \mathrm{Fe}_{2} \mathrm{O}_{4}$ samples ( $\mathrm{x}=0.00,0.25$, $0.50, .0 .75,1.00)$ are shown in Fig. 2. The formation of $\mathrm{Cd}_{1-\mathrm{x}} \mathrm{Mn}_{\mathrm{x}} \mathrm{Fe}_{2} \mathrm{O}_{4}$ phase with a facecentered cubic spinel structure with a space group of $\mathrm{Fd} 3 \mathrm{~m}$ was revealed in the figure. All the characteristic reflections correlate well with JCPDS cards 22-1086 and 10-0325, indicating construction of spinel ferrites in the prepared samples. In addation, XRD patterns for samples with $\mathrm{x}=0,0.25,0.5$ showed peaks of the hemitate hexagonal phase $\alpha-\mathrm{Fe}_{2} \mathrm{O}_{3}$ (JCPDS\#86-0550) with lattice parameter $a=b=5.21 \AA, c=13.45 \AA$ and space group R-3c, marked with (*). The formation of hemitate hexagonal phase $\alpha-\mathrm{Fe}_{2} \mathrm{O}_{3}$ could be attributed to very slow diffusion of $\mathrm{Cd}$ ions into ferrite matrix [15].

Among the different quantitative methods for studying materials from powder diffraction data, the Rietveld method [16] still widely applied as it presents whole-pattern fitting approach 
rather than single-peak analysis. The Rietveld refinement of diffraction patterns for samples with $x=0,0.5$ and 1.0 has been performed and shown in Fig. 3. As seen, the figure confirmed that the samples with $x=0$ and $\mathrm{x}=0.5$ contain two phases; cubic spinel phase with space group $\mathrm{Fd} 3 \mathrm{~m}$ and hemitate hexagonal phase $\alpha-\mathrm{Fe}_{2} \mathrm{O}_{3}$ of the space group R-3c. The volume fraction of the hemitate hexagonal phase $\alpha-\mathrm{Fe}_{2} \mathrm{O}_{3}$ was found to decrease with incrasing of Mn-content.

The XRD spectra revealed a shift towards lower $2 \theta$ angle in the noticeable (311) peak, Fig. 2, of the cubic spinel phase with the increase in manganese content. The observed peaks shift is in agreement with the difference in ionic radii of the cadmium and manganese [17]. The lattice parameters of the cubic spinel phase have been calculated by using Full-Prof program (Le Bail fit) and data are listed in Table 1. It is obviously realized that the lattice parameters decreased with increasing Mn concentration. This could be mainly related to the difference in ionic radii of $\mathrm{Cd}^{2+}(0.97 \AA \AA)$ and $\mathrm{Mn}^{2+}(0.80 \AA ̊)$ [17]. The decrease in lattice parameters of the main cubic spinel phase is a good indication that $\mathrm{Mn}^{2+}$ ions substitute $\mathrm{Cd}^{2+}$ ions in these ferrites.

Using the Scherrer formula (Eqn. 2) [18], the average crystallite size of the samples was approximately calculated based on the X-ray Miller indices (220), (311), (222), (400), (422) and (440):

$$
D=\frac{\mathrm{k} \lambda}{\beta \cos \theta}
$$

where D is the average crystallite size, $\mathrm{k}$ is Scherrer's constant with a value of 0.94 for spherical crystals with cubic symmetry, $\lambda$ is the wavelength of $X$-ray radiation , $\beta$ is the full width at halfmaximum and $\theta$ is the angle of diffraction.

The theoretical X-ray density $\left(\rho_{\mathrm{x}}\right)$ has been estimated by means of Eqn. (3) [19]:

$$
\rho_{x}=\frac{Z M}{N_{A} a^{3}}
$$

where $M$ is molecular mass, $N_{A}$ is Avogadro's number, $\mathrm{Z}=8$ and signifies the number of molecules per spinel unit cell and $a$ is the lattice constant. Table 1 lists variation of calculated theoretical density with Mn-content (x). The observed decrease in $\rho_{x}$ with $\mathrm{x}$ is referred to the decrease in the molecular weight of prepared samples due to the difference in atomic weight and density of $\mathrm{Cd}$ and $\mathrm{Mn}$. 
The variation of distances between magnetic ions (hopping length of tetrahedral site $\left(\mathrm{L}_{\mathrm{A}}\right)$ and hopping length of octahedral site $\left.\left(\mathrm{L}_{\mathrm{B}}\right)\right)$ were calculated by applying Eqns. $(4,5)[20]$ :

$$
\begin{aligned}
& L_{A}=\frac{a \sqrt{3}}{4} \\
& L_{B}=\frac{a \sqrt{2}}{4}
\end{aligned}
$$

Hoping lengths were found to decrease with increasing manganese content, see Table 1 . This may be ascribed to the decrease in lattice parameter of all the samples by increasing $\mathrm{Mn}^{2+}$ ions. XRD data may be used to determine the cation distribution in spinel ferrites using reflections (220), (440), and (400) [21]. In $\mathrm{Cd}_{1-\mathrm{x}} \mathrm{Mn}_{\mathrm{x}} \mathrm{Fe}_{2} \mathrm{O}_{4}$, ions of cadmium favor to inhabit the tetrahedral sites, unlike the ions of manganese that favor octahedral sites [22]. However, ferric ions are expected to occupy both tetrahedral and octahedral positions. Therefore, when a substantial number of $\mathrm{Mn}^{2+}$ ions substitutes $\mathrm{Cd}^{2+}$, ferric ions are expected to migrate from octahedral sites into tetrahedral sites.

\subsection{Scanning electron Microscope and EDX analysis:}

Surface morphological properties of the cadmium-manganese ferrite samples were investigated by using scanning electron microscopy (SEM). Figure 4 (a) shows the SEM micrographs of $\mathrm{Fe}_{2} \mathrm{Cd}_{1-\mathrm{x}} \mathrm{Mn}_{\mathrm{x}} \mathrm{O}_{4}(\mathrm{x}=0.0,0.5$ and 1.0) samples; the distribution of particles is homogenous. These Micrographs reveal that the samples contain nanoparticles agglomeration of uniform grains due to their mutual magnetic interactions and high surface energy. SEM images obviously revealed that the particle size increases with increasing of Mn-content (x), Fig.4 (b), in harmony with particle size results of $\mathrm{X}$-ray diffraction analysis.

Figure 5 reveals energy-dispersive X-ray spectroscopy (EDX) charts of $\mathrm{Cd}_{1-\mathrm{x}} \mathrm{Mn}_{\mathrm{x}} \mathrm{Fe}_{2} \mathrm{O}_{4}$ ferrites for $\mathrm{x}=0.0,0.5$ and 1.0 samples. The undoped sample, $\mathrm{x}=0$, displays no trace of impurities or Mn element.. As observed, increasing Mn-content (x) is reflected in increasing the intensity of of its peaks and its real weight percent is tabulated in Table 2. 


\subsection{FTIR analysis:}

Figure 6 shows Fourier-Transform Infrared spectroscopy (FTIR) measurements of $\mathrm{Fe}_{2} \mathrm{Cd}_{1-}$ ${ }_{x} \mathrm{Mn}_{\mathrm{x}} \mathrm{O}_{4}$ nanoparticles in the range $400-4000 \mathrm{~cm}^{-1}$. The broad absorption band at around $3460 \mathrm{~cm}^{-}$ 1 is attributed to stretching vibrations of hydroxy $(\mathrm{O}-\mathrm{H})$ group due to adsorption of water molecules at the surface $[13,14]$. The band around $1636 \mathrm{~cm}^{-1}$ is assigned to bending vibration of water molecules $[25,26]$, whereas the band at $1377 \mathrm{~cm}^{-1}$ to trapped nitrates in prepared ferrites [27]. The absorption bands in the range $400-750 \mathrm{~cm}^{-1}$ reflect the fundamental lattice vibrations of the crystal lattice. The bands in the range $560-590 \mathrm{~cm}^{-1}$ and $468-477 \mathrm{~cm}^{-1}$ are assigned to tetrahedral $\left(v_{t}\right)$ and octahedral $\left(v_{0}\right)$ stretching vibrations of metal ion and oxygen (M-O) complex. The higher values of $v_{t}$ as compared to $v_{o}$ is referred to the short bond length of tetrahedral coordination as compared to octahedral one. The presence of these two fundamental peaks confirms the spinel structure of prepared ferrites [28] as revealed by XRD analysis.

Figure 7 shows deconvolution of absorption spectra in the range $400-800 \mathrm{~cm}^{-1}$. For $\mathrm{x}=0.0$ $\left(\mathrm{CdFe}_{2} \mathrm{O}_{4}\right)$, the peak at $453 \mathrm{~cm}^{-1}$ is assigned to $\alpha-\mathrm{Fe}_{2} \mathrm{O}_{3}$ impurity phase [29,30], whereas $v_{\mathrm{t}}$ and $v_{0}$ are observed at 560 and $477 \mathrm{~cm}^{-1}$, respectively. As observed, the increase in Mn-content (x) causes a decrease in the intensity of $\alpha-\mathrm{Fe}_{2} \mathrm{O}_{3}$ peak and vanished for $\mathrm{x}=1.0$ sample $\left(\mathrm{MnFe}_{2} \mathrm{O}_{4}\right)$ in consonance with XRD results. The observed shoulders of tetrahedral bands were clarified by deconvolution and ascribed to Jahn-Teller distortion due to bonding of oxygen ions with divalent $\mathrm{Cd}, \mathrm{Mn}$, and Fe ions [31].

Figure 8 depicts the variation of $v_{t}$ and $v_{0}$ with the increase in Mn-content (x). It has been reported $[32,33]$ that the nonmagnetic divalent $\mathrm{Cd}^{2+}$ ions prefers to occupy the tetrahedral sites and forces $\mathrm{Fe}$ ions to inhabit the octahedral sites forming normal $\mathrm{CdFe}_{2} \mathrm{O}_{4}$ spinel ferrite for $\mathrm{x}=0$. As the magnetic divalent $\mathrm{Mn}^{2+}$ increases with the increase in $\mathrm{x}$; inverse spinel ferrites are developed with preferred residence of $\mathrm{Mn}^{2+}$ ions in the octahedral sites [34]. Therefore, the decrease in $\mathrm{Cd}^{2+}$ content upon the increase in $\mathrm{x}$ is compensated by the transfer of $\mathrm{Fe}^{3+}$ ions from octahedral to tetrahedral sites. This resulted not only in the increase in $v_{t}$ with the increase in $\mathrm{x}$, but the decrease in $v_{0}$ with the increase in $\mathrm{x}$, as well. This could be attributed to the fact that the ionic radius of $\mathrm{Fe}^{3+}$ is smaller than that of $\mathrm{Cd}^{2+}$ which causes a decrease in $\mathrm{Fe}-\mathrm{O}$ bond length and consequently a shift in $v_{t}$ towards higher energy [35]. On the other hand, this migrated $\mathrm{Fe}^{3+}$ ions from octahedral sites are replaced by $\mathrm{Mn}^{2+}$ ions with ionic radius greater than that of $\mathrm{Fe}^{3+}$ and 
consequently a shift towards lower energy is observed in $v_{0}$ with the increase in Mn-content. Finally, the strong variation of $v_{\mathrm{t}}$ with $\mathrm{x}$ as compared to $v_{\mathrm{o}}$ could be attributed to the large difference between ionic radii of $\mathrm{Fe}^{3+}$ and $\mathrm{Cd}^{2+}$ as compared to that of $\mathrm{Mn}^{2+}$ and $\mathrm{Fe}^{3+}$ radii. Table 3 lists band positions of $v_{\mathrm{t}}$ and $v_{\mathrm{o}}$ stretching vibrations, corresponding force constants $k_{\mathrm{t}}$ and $k_{\mathrm{o}}$ and mean force constant $k_{\mathrm{m}}$. These force constants were calculated by employing Waldorn method $(6,7)[30]$ as:

$$
\begin{aligned}
& k_{t}=7.62 \times M_{t} \times v_{t}^{2} \times 10^{-7} \mathrm{~N} / \mathrm{m} \\
& k_{o}=5.31 \times M_{o} \times v_{o}^{2} \times 10^{-7} \mathrm{~N} / \mathrm{m}
\end{aligned}
$$

where $M_{t}$ and $M_{o}$ are molecular weights of tetrahedral and octahedral cations, respectively. The variation of force constants with Mn-content is listed in Table 3. It worth to mention that even though tetrahedral vibrations $\left(v_{t}\right)$ increased with the increase in $x$, the corresponding force constant $k_{t}$ decreased which is attributed to the large difference of molecular weight of $\mathrm{Cd}$ as compared to $\mathrm{Mn}$ and Fe. Therefore, the listed decrease in mean force constant $k_{m}$ upon replacing $\mathrm{Cd}$ ions by $\mathrm{Mn}$ ions (Table 3) suggests weakening of interatomic binding as a result of altering both bond lengths and molecular weight of these cations.

The elastic constants of a material are of much importance in determination of its response/deformation to an applied force. Spinel ferrites are considered as homogenous and isotropic solids and identifying its reduced elastic constants are important for engineering applications. Since spinel ferrites are isotropic and homogenous materials with cubic symmetry, the components of elasticity tensor $C_{11}$ and $C_{12}$ are almost equal. The longitudinal elastic wave velocity $\left(V_{l}\right)$, transverse elastic waves velocity $\left(V_{t}\right)$, mean elastic wave velocity $\left(V_{m}\right)$, bulk modulus $(B)$, rigidity modulus $(G)$, Young modulus $(E)$, Poisson ratio $(\sigma)$ and Debye temperature $\left(\theta_{D}\right)$ were calculated using the following relations (8-16) [36-41].

$$
\begin{gathered}
C_{11}=C_{12}=k_{m} / a \\
V_{l}=\sqrt{C_{11} / \rho_{x}} \\
V_{t}=\sqrt{C_{11} / 3 \rho_{x}} \\
V_{m}=\left[\frac{1}{3}\left(\frac{2}{V_{t}^{3}}+\frac{1}{V_{l}^{3}}\right)\right]^{-1 / 3}
\end{gathered}
$$




$$
\begin{gathered}
B=\frac{1}{3}\left(c_{11}+2 c_{12}\right) \\
G=\rho_{x} v_{t}^{2} \\
\sigma=(3 B-2 G) /(6 B+2 G) \\
E=(1+\sigma) 2 G \\
\theta_{D}=\frac{h}{k_{B}}\left(\frac{3 N_{A}}{4 \pi V_{A}}\right)^{1 / 3} V_{m}
\end{gathered}
$$

where $k_{m}$ is mean force constant, $a$ is lattice parameter, $\rho_{x}$ is x-ray density, $h$ is Planck's constant, $k_{B}$ is Boltzmann's constant, $N_{A}$ is Avogadro's number and $V_{A}$ is mean atomic volume. Table 4 shows the calculated elastic parameters for different Mn-content. Longitudinal, transverse and mean elastic wave velocities $\left(V_{l}, V_{t} V_{m}\right)$ (Fig. 9), bulk modulus (B), rigidity modulus $(G)$, Young modulus $(E)$ (Fig. 10) and Debye temperature $\left(\theta_{D}\right)$ decreased with the increase in Mn-content. This could be attributed to the fact that the listed relations of elastic moduli depend mainly on the mean force constant which was found to decrease with the increase in Mn-content as discussed above. The listed Poisson ratio $\sigma$ unaltered under variation in $\mathrm{Mn}$ content with a value of 0.35 which confirms the isotropic elasticity of these ferrites as it lies within the proposed limit of -1 to 0.5 . The listed values of Debye temperature $\left(\theta_{D}\right)$ showed its decrease with increasing Mn-content (x) which suggests that $\mathrm{Mn}$ substitution assisted lattice vibrations as a consequence of the reported weakening of interatomic bonding. The listed values of characteristic peaks, force constants and elastic moduli are in fair agreement with other reported data, see for example Refs. [42, 43].

\subsection{Magnetic Properties}

Magnetic hysteresis loop displays the history of magnetization in magnetic materials and gives unique criteria for determining spin ordering. The $\mathrm{M}-\mathrm{H}$ hysteresis loops of $\mathrm{Fe}_{2} \mathrm{Cd}_{1-\mathrm{x}} \mathrm{Mn}_{\mathrm{x}} \mathrm{O}_{4}$ samples $(\mathrm{x}=0.0,0.25,0.5, .0 .75,1.0)$ are illustrated in Fig. 11. The magnetic properties such as saturation magnetization $\left(\mathrm{M}_{\mathrm{s}}\right)$, magnetic moment $\left(\eta_{\mathrm{B}}\right)$, Coercivity $\left(\mathrm{H}_{\mathrm{c}}\right)$, retentivity $\left(\mathrm{M}_{\mathrm{r}}\right)$ and anisotropy constant $(\mathrm{K})$ are given in Table 5 . Saturation magnetization $\left(\mathrm{M}_{\mathrm{s}}\right)$ was revealed to increase with increasing $\mathrm{Mn}^{2+}$ content up to $x=1.0$, as shown in Fig.12. The increasing trend of $M_{s}$ might be ascribed to 
many factors. The first one is going to substitution of small magnetic moment $\mathrm{Cd}^{2+}$ $\left(\mathrm{d}^{10}\right)$ ions by large magnetic moment $\mathrm{Mn}^{2+}\left(\mathrm{d}^{5}\right)$ ions [44]. The second factor is the particle size which increased with increasing Mn-content, for instance, sample with $\mathrm{x}=1.0$ with larger particle size showed higher $\mathrm{M}_{\mathrm{s}}$ as compared to other samples, Table 1. Another important factor, the difference in saturation magnetization of specimens with variable $\mathrm{Mn}^{2+}$ concentration (x) is largely determined by cation distribution and super-exchange process that occurs between Fe-ions and Mn-ions at tetrahedral (A) and octahedral (B) sites. Since the cation distribution revealed that $\mathrm{Mn}^{2+}$ ions occupied the B-sites, some $\mathrm{Fe}$ ions from these sites migrates to A-sites as $\mathrm{Mn}$ increased. As the concentration of $\mathrm{Fe}$ ions at A-sites grow, its magnetic moment rises and magnetic moment of B-sites declines. As a result, magnetization of the $\mathrm{A}$ sub-lattice decreased, resulting in an increase in net magnetization $\left(M=M_{B}-M_{A}\right)$.

The coercivity $\left(H_{\mathrm{c}}\right)$ is the intensity of magnetic field necessary to decrease the magnetization of samples to zero. As seen in Fig. 12, the coercivity $\left(H_{\mathrm{c}}\right)$ decreases with increasing Mn-content. The decreasing of coercivity $\left(H_{\mathrm{c}}\right)$ results in increasing the grain size and decreasing of residual $\alpha-\mathrm{Fe}_{2} \mathrm{O}_{3}$ having a high intrinsic coercive force [45].

Consistent with the Stoner Wohlfarth model [46], coercivity is inversely proportional to saturation magnetization as stated by Eqn. (17):

$$
H_{c}=\frac{2 \mathrm{~K}}{M_{S}} \times \mu_{B}
$$

where $\mathrm{K}$ is the anisotropy constant, $\mu_{B}$ is the universal constant of permeability at free space and $M_{s}$ is the saturation magnetization.

Using the following relation (18) [47], the magnetic moment per formula unit in Bohr magnetron (B) was computed:

$$
\mu_{B}=\mathbf{M}_{\mathbf{w}} \times \frac{M_{S}}{\mathbf{5 5 8 5}}
$$

where $\mathrm{M}_{\mathrm{W}}$ is the molecular weight of the sample and $\mathrm{M}_{\mathrm{S}}$ is the saturation magnetization in the electromagnetic unit. Table 5 shows the difference of magnetic 
moment with Mn concentration. Due to the increase in saturation magnetization, the magnetic moment of samples rises with Mn-content in Cd-Mn ferrite.

\subsection{Dielectric and electrical investigations}

The dielectric and electrical measurements of the samples $\mathrm{Fe}_{2} \mathrm{Cd}_{1-\mathrm{x}} \mathrm{Mn}_{\mathrm{x}} \mathrm{O}_{4}$ with $\mathrm{x}=0.0,0.25$, $0.5,0.75,1.0$ have been carried out on a broad frequency range to show the effect of structure and synthesis process employed for fabrication. Figure 13 represents the frequency dependence of the dielectric constant of the as-prepared $\mathrm{Fe}_{2} \mathrm{Cd}_{1-\mathrm{x}} \mathrm{Mn}_{\mathrm{x}} \mathrm{O}_{4}$ nanoparticles. The figure reflects a super-position of polarization of the dipoles originated from the charge transfer among the divalent and tri-valent cations inside the spinel structure and the contribution of charge carriers' transport. Important information such as polarization mechanism and localized electric charge carriers in ferrites can be deduced from dielectric spectra. The frequency dependence of permittivity undergoes a gradual decrease throughout the frequency range in three distinguished trends. The first trend, a sharp decrease with frequency up to $100 \mathrm{~Hz}$, followed by a warp-like behavior and then slow decrease accompanied by a collapse in all samples under investigation.

The permittivity increases, generally, with the increase of $\mathrm{Mn}^{2+}$ concentration. This is accompanied by a remarkable attenuation of the secondary phases however, the number of $\mathrm{Fe}^{3+}$ ions at B-sites increase through the increase of grain size. Transport of $\mathrm{Fe}^{3+}$ under the effect of the external electric field results in the growth of $\mathrm{Fe}^{2+} \leftrightarrow \mathrm{Fe}^{3+}$ ion-pairs at B-sites and hence the interfacial polarization rises through the increase of grain size. Similar interpretation was discussed very recently by Dubey and Lahiri [48]. This confirms the tendency of ferromagnetic behavior to switch to paramagnetic as a result of $\mathrm{Fe}^{3+}$ migration with the growth of grain size of $\mathrm{Cd}_{1-\mathrm{x}} \mathrm{Mn}_{\mathrm{x}} \mathrm{Fe}_{2} \mathrm{O}_{4}$ ferrite nanoparticles. Additionally, at higher frequencies, exchange of electrons between $\mathrm{Fe}^{2+}$ and $\mathrm{Fe}^{3+}$ ions cannot follow the applied $\mathrm{AC}$ electric field reflecting in the attenuation of dielectric constant.

Similar behavior is noticed for the dielectric loss $\left(\varepsilon^{\prime \prime}\right)$, confirming the fact that both parts of the complex dielectric function $\left(\varepsilon^{\prime}\right.$ and $\left.\varepsilon^{\prime \prime}\right)$ are not independent. The splitting out of the dielectric parameters of the different samples with sharp decrease as frequency increases is due to conductivity contribution. This confirms the governing equation that describes the relationship between the complex conductivity and dielectric functions. 
The observed bend at the intermediate frequency range is attributed to the space-charge polarization at the grain boundaries. This generates a potential barrier, and therefore, the charge carriers accumulate at the grain boundary. The space charge polarization can be explained by Maxwell-Wagner-Siller (MWS-type) polarization processes usually found in inhomogeneous medium containing of conducting grains separated by grain boundaries of high electrical resistivity [49-52]. At the region of high-frequency, the space charge polarization consequence is decreased, and the hopping rate of charge carriers lags behind that of the applied electric field. This explains the close- in addition to the reduction- of $\varepsilon^{\prime}$ values for all the five investigated samples. The extremely high values of $\varepsilon^{\prime}$ and $\varepsilon^{\prime \prime}$ at lower frequencies (typically $10^{-5}$ to $10^{6}$ at 0.1 $\mathrm{Hz}$ ) reflecting the high effect of dc-conductivity on the dielectric parameters as frequency decreases. This confirms the relationship between complex permittivity and conductivity as stated before.

The dependence of the real part of complex conductivity $\left(\sigma^{\prime}\right)$ on frequency for the asprepared $\mathrm{Cd}_{1-\mathrm{x}} \mathrm{Mn}_{\mathrm{x}} \mathrm{Fe}_{2} \mathrm{O}_{4}$ ferrites at room temperature is illustrated in Fig. 14. The frequency dependence of $\sigma^{\prime}$ follows the following empirical Jonscher equation (19) [53], as was recently found in many conductive glasses as well as polymeric systems [52, 54, and 55],

$$
\boldsymbol{\sigma}^{\prime}(\boldsymbol{v})=\boldsymbol{\sigma}_{\boldsymbol{d c}}\left[\mathbf{1}+\left(\frac{\boldsymbol{v}}{\boldsymbol{v}_{\boldsymbol{c}}}\right)^{\boldsymbol{n}}\right], \text { where }:(0<n \leq 1)
$$

At lower frequencies, the actual component of conductivity appears to be smaller or even develops a separate frequency trajectory. This plateau yields directly the dc-conductivity $\left(\sigma_{\mathrm{dc}}\right)$ and the characteristic frequency $\left(v_{c}\right)$, at which the dispersion of $\sigma^{\prime}$ sets in and turns into a power law at higher frequencies. Three fitting parameters are illustrated graphically against $\mathrm{Mn}$ concentration in Fig. 15. It is obvious from the figure that, to some extent, $v_{\mathrm{c}}$ and $\sigma_{\mathrm{dc}}$ behave in similar manner as a function of Mn-content. This can be explained by considering that the characteristic frequency is related directly to the reciprocal of the hopping time that characterizes the transport of charge carriers. Therefore, it is reasonable to observe a gradual increase of dcconductivity with the characteristic frequency which confirms the well-known Barton-Nakajima -Namikawa (BNN) relation expressed as:

$$
\sigma_{d c}=p \varepsilon_{o} \Delta \varepsilon 2 \pi v_{c}
$$


where $p$ is a numerical constant of order $1, \varepsilon_{o}$ the permittivity of vacuum and $\Delta \varepsilon$ the relaxation strength. This can also be expressed as: $\sigma_{d c} \sim v_{c}$.

The inset of Fig. 15 depicts the Mn concentration dependence of the exponential parameter $\mathrm{n}$. As seen, it decreases linearly as Mn concentration increases that explain why the curves became close to each other as the frequency increases.

\section{Conclusion:}

$\mathrm{Fe}_{2} \mathrm{Cd}_{1-\mathrm{x}} \mathrm{Mn}_{\mathrm{x}} \mathrm{O}_{4}$ spinel ferrite nanoparticles were prepared by using flash auto-combustion method. X-ray diffraction study confirmed the synthesis of the main cubic phase with space group $\mathrm{Fd} 3 \mathrm{~m}$ in all samples in addition to hemitate hexagonal phase $\alpha-\mathrm{Fe}_{2} \mathrm{O}_{3}$ in samples with $\mathrm{x} \leq$ 0.5. The substitution of manganese caused a compression in the crystal lattice of the cubic phase and an enlargement of the particle size. The observed $\alpha-\mathrm{Fe}_{2} \mathrm{O}_{3}$ impurity phase by XRD study was confirmed by FTIR analysis. The study showed the presence of the two fundamental tetrahedral and octahedral stretching vibrations of metal ion-oxygen bands in the range 560-590 cm-1 and 468-477 $\mathrm{cm}^{-1}$, confirming spinel structure of prepared ferrites. The dependence of the fundamental vibrations on Mn-content was studied and explained in terms of $\mathrm{Fe} 3+$ ions migration from octahedral to tetrahedral sites. FTIR was employed to calculate wave velocities, elastic moduli and Debye temperature and their behavior with Mn concentration was explained. Magnetic measurements revealed an increase in both saturation magnetization and magnetic moment with increasing of Mn-content, whereas coercivity demonstrated an inverse dependence on $\mathrm{x}$. The electrical properties of the prepared $\mathrm{Mn}-\mathrm{Cd}$ spinel nano-ferrites were investigated using a broadband dielectric spectroscopy at room temperature and over a broad range of frequencies from $10^{-1}$ up to $10^{7} \mathrm{~Hz}$. The substitution of $\mathrm{Cd}$ by $\mathrm{Mn}$ resulted generally in remarkable increase of permittivity and electrical conductivity as well, especially at lower frequencies. This reflects the conductivity contribution accompanied by the interfacial polarization that increases with the increase of grain size and also the effect of exchange of electron between $\mathrm{Fe}^{2+}$ and $\mathrm{Fe}^{3+}$ ions. The frequency dependence of real part of complex conductivity shows plateau yields the dc-conductivity, $\sigma_{\mathrm{dc}}$, at lower frequencies inversely proportional to hopping time in well agreement with BNN-relation 


\section{References:}

1. A. Gholizadeh, A. Malekzadeh, M. Ghiasi, Structural and magnetic features of La ${ }_{0.7} \mathrm{Sr}_{0.3} \mathrm{Mn}_{1-\mathrm{x}} \mathrm{Co}_{\mathrm{x}} \mathrm{O}_{3}$ nano-catalysts for ethane combustion and $\mathrm{CO}$ oxidation. Ceram. Int. 42(5), 5707-5717 (2016).

2. S. Mahmoudi, A. Gholizadeh, Effect of non-magnetic ions substitution on the structure and magnetic properties of $\mathrm{Y}_{3-\mathrm{x}} \mathrm{Sr}_{\mathrm{x}} \mathrm{Fe}_{5-\mathrm{x}} \mathrm{Zr}_{\mathrm{x}} \mathrm{O}_{12}$ nanoparticles. J. Magn. Magn. Mater. 456, 46-55(2018).

3. A. Manikandan, J. J. Vijaya, L. J. Kennedy, M. Bououdina, Structural, optical and magnetic properties of $\mathrm{Zn}_{1-\mathrm{x}} \mathrm{Cu}_{\mathrm{x}} \mathrm{Fe}_{2} \mathrm{O}_{4}$ nanoparticles prepared by microwave combustion method. J. Mol. Struct. 1035, 332-340(2013).

4. L. Chun, H. Xiaopeng, C. Fangyi, H. Yuxiang, C. Chengcheng, C. Jun, Phase and composition controllable synthesis of cobalt manganese spinel nanoparticles towards efficient oxygen electrocatalysis. Nat Commun. 6, 7345 (2015)

5. Z. K. Heiba, M.B. Mohamed, Structural phase analysis, optical and magnetic properties of nano Mn-doped $\mathrm{LiFe}_{5} \mathrm{O}_{8}$, Appl Phys A 124(12), 818 (2018).

6. S. Singhal, S. Jauhar, K. Chandra, S. Bansal, Spin canting phenomenon in cadmium doped cobalt ferrites, $\mathrm{CoCd}_{\mathrm{x}} \mathrm{Fe}_{2-}{ }_{\mathrm{x}} \mathrm{O}_{4}(\mathrm{x}=0 \cdot 0,0 \cdot 2,0 \cdot 4,0 \cdot 6,0 \cdot 8$ and 1.0), synthesized using sol-gel auto combustion method. Bull Mater Sci 36(1):107-114 (2013).F. Li, H. Wang, L. Wang, J. Wang . Magnetic properties of $\mathrm{ZnFe}_{2} \mathrm{O}_{4}$ nanoparticles produced by a lowtemperature solid-state reaction method. J Magn Magn Mater. 309, 295-299 (2007).

7. S. Hazra, N. N. Ghosh, Preparation of Nanoferrites and Their Applications, Journal of Nanoscience and Nanotechnology, 14, 2, 1983-2000(18) (2014).

8. Z. Wang, Y. Xie, P. Wang, Y. Ma, S. Jin, X. Liu, Microwave anneal effect on magnetic properties of $\mathrm{Ni}_{0.6} \mathrm{Zn}_{0.4} \mathrm{Fe}_{2} \mathrm{O}_{4}$ nanoparticles prepared by conventional hydrothermal method. J Magn Magn Mater.; 323, 3121-3125 (2011).

9. R. K. Sharma, R. Ghose, Synthesis and characterization of nanocrystalline zinc ferrite spinel powders by homogeneous precipitation method, Ceram Int. 41,14684-14691 (2015).

10. G. Vaidyanathan, S. Sendhilnathan, Characterization of $\mathrm{Co}_{1-\mathrm{x}} \mathrm{Zn}_{\mathrm{x}} \mathrm{Fe}_{2} \mathrm{O}_{4}$ nanoparticles synthesized by co-precipitation method. Physica B Condens Matter. 403, 2157-2167 (2008) . 
11. A. T. Raghavender, N. Biliškov, Z. Skoko, XRD and IR analysis of nanocrystalline NiZn ferrite synthesized by the sol-gel method. Mater Lett. 65, 677-680 (2011).

12. H. K. Dubey, C. Verma, U. S. Rai, A. kumar, P. Lahiri, Synthesis characterization and properties of nickel-based zinc ferrite nanoparticles. Ind J Chem A. 58, 454-458 (2019).

13. S. Yadav, S. Shinde, P. Bhatt, S. Meena, K. Rajpure, Distribution of cations in $\mathrm{Co}_{1-\mathrm{x}} \mathrm{Mn}_{\mathrm{x}} \mathrm{Fe}_{2} \mathrm{O}_{4}$ using XRD, magnetization and Mössbauer spectroscopy. J Alloy Compd 646:550-556 (2015).

14. W. S. Mohamed, M. Alzaid, M. S. M. Abdelbaky, Z. Amghouz, S. García-Granda, A. M. Abu-Dief, Impact of $\mathrm{Co}^{2+}$ Substitution on Microstructure and Magnetic Properties of $\mathrm{Co}_{\mathrm{x}} \mathrm{Zn}_{1-\mathrm{x}} \mathrm{Fe}_{2} \mathrm{O}_{4}$ Nanoparticles, Nanomaterials (Basel). 2019 9(11): 1602 (2019).

15. M. Sinha, S. K. Pradhan, Synthesis of nanocrystalline $\mathrm{Cd}-\mathrm{Zn}$ ferrite by ball milling and itsstability at elevated temperatures, Journal of Alloys and Compounds, 489, 91-98 (2010).

16. H. M. Rietveld, A profile refinement method for nuclear and magnetic structures, J. Appl. Cryst. 2, 65-71 (1969).

17. R.D. Shannon, Revised effective ionic radii and systematic studies of interatomic distances in halides and chalcogenides, Acta Crystallogr. Sect. A. (1976).

18. H. P. Klung, L. B. Alexander, X-ray diffraction procedures.New York USA: Wiley; 1974.

19. D.V. Kurmude, R.S. Barkule, A.V. Raut, D.R. Shengule, K.M. Jadhav, X-Ray Diffraction and Cation Distribution Studies in Zinc-Substituted Nickel Ferrite Nanoparticles, J Supercond Nov Magn 27:547-553 (2014).

20. M Satalkar, S N Kane, On the study of Structural properties and Cation distribution of $\mathrm{Zn}_{0.75-\mathrm{x}} \mathrm{Ni}_{\mathrm{x}} \mathrm{Mg}_{0.15} \mathrm{Cu}_{0.1} \mathrm{Fe}_{2} \mathrm{O}_{4}$ nano ferrite: Effect of $\mathrm{Ni}$ addition, Journal of Physics: Conference Series 755012050 (2016).

21. H. K. Dubey, P. Lahiri, Synthesis, structural, dielectric and magnetic properties of $\mathrm{Cd}^{2+}$ based Mn nanosized ferrites, Materials Technology, DOI:10.1080/10667857.2020.1734728 (2020).

22. J. M. D. COEY, Magnetism and Magnetic Materials, United States of America by Cambridge University Press, New York (2010). 
23. J. L. Jambor, J. E. Dutrizac, Occurrence and Constitution of Natural and Synthetic Ferrihydrite, a Widespread Iron Oxyhydroxide, Chem. Rev. 98, 2549-2586 (1998).

24. H. Fan, B. Song, Z. Yang, Q. Li, Induced nucleation of haematite nanoparticles with superparamagnetic properties, Nanotechnology. 16, 1100 (2005).

25. E. B. Slamovich, I. A. Aksay, Structure Evolution in Hydrothermally Processed $\left(<100^{\circ} \mathrm{C}\right) \mathrm{BaTiO}_{3}$ Films,J. Am. Ceram. Soc. 79, 239 (1996).

26. S. Li, S. R. Condrate, S. D. Jang, R. M. Spriggs, FTIR and Raman spectral study of the preparation of lead zirconate $\left(\mathrm{PbZrO}_{3}\right)$ by a solgel process in a non-flowing air atmosphere, J. Mater. Sci. 24, 3873 (1989).

27. I. Nakagawa, J. L. Walter, Optically Active Crystal Vibrations of the Alkali-Metal Nitrates,J. Chem. Phys. 51, 1389 (1969).

28. Suman, S. Chahal, A. Kumar, P. Kumar, Zn Doped $\alpha$-Fe2O3: An Efficient Material for UV Driven Photocatalysis and Electrical Conductivity. Crystals, 10(4), 273 (2020).

29. A.T. Raghavender, N. Biliškov, Ž. Skoko, XRD and IR analysis of nanocrystalline Ni-Zn ferrite synthesized by the sol-gel method, Materials Letters 65, 677-680 (2011).

30. R. D.Waldron, Infrared spectra of ferrites. Phys Rev.;99, 1727-1735 (1955).

31. K. A. Mohammed, A. D. Al-Rawas, A. M. Gismelseed, A. Sellai, H. M. Widatallah, A. Yousif, M. E. Elzain, M. Shongwe, Infrared and structural studies of $\mathrm{Mg}_{1-\mathrm{X}} \mathrm{Zn}_{\mathrm{X}} \mathrm{Fe}_{2} \mathrm{O}_{4}$ ferrites. Phys. B 407, 795-804 (2012).

32. S. W. Jong, P. D. 1 Ownby, IEEE Transactions on Magnetics 416-422 (1974).

33. S. A. Mazen, A. E. Abd-El-Rahiem, B. A. Sabrah, J. Of Materials Science 22, 4177-4180 (1987).

34. S. J. Haralkar, R. H. Kadam, S. S. More,. Substitutional effect of $\mathrm{Cr} 3+$ ions on the properties of $\mathrm{Mg}-\mathrm{Zn}$ ferrite nanoparticles. Physica B Condens Matter. 407, 4338-4346 (2012).

35. F.S. Tehrani, V. Daadmehr, A. T. Rezakhani, R. H. Akbarnejad, S. Gholipour, J. Supercond. Novel Magn., 25, 2449 (2012).

36. K. B. Modi, U. N. Trivedi, M. P. Pandya, S. S. Bhatu, M. C. Chhantbar, and H. H. Joshi, Microwaves and Optoelectronics, Anamaya Publishers, New Delhi, India, (2004).

37. K . B. Modi, Elastic moduli determination through IR spectroscopy for zinc substituted copper ferri chromates, Journal of Materials Science, vol. 39, no. 8, pp. 2887-2890, (2004). 
38. K. B. Modi, P. U. Sharma, M. C. Chhantbar, and H. H. Joshi, "Elastic constants determination for $\mathrm{Fe}^{3+}$ substituted YIG through infra-red spectroscopy and heterogeneous metal mixture rule," Journal of Materials Science, vol. 40, no. 5, p. 1247, (2005).

39. D. Ravinder and T. A. Manga, "Elastic behaviour of Ni-Cd ferrites," Materials Letters, vol. 41, no. 5, pp. 254-260, (1999).

40. B. Raj, V. Rajendram, and P. Palanichamy, Science and Technology of Ultrasonics, Narosa Publishing House, New Delhi, India, (2004.)

41. O. L. Anderson "Physics Acoustics" edited by W P Mason, Vol 3BC (Academic Press, New York), p 45 (1965).

42. S. Galagali, R. Patil, R. Adaki, C. Hiremath, S. Mathad, A. Pujar, R. Pujar, Fourier transform infrared spectroscopy and elastic properties of $\mathrm{Mg}_{1-\mathrm{x}} \mathrm{Cd}_{\mathrm{x}} \mathrm{Fe}_{2} \mathrm{O}_{4}$ ferrite systems, J. Sci. Technol. 41 (5), 992-998(2019).

43. K. B. Modi, M. K. Rangolia, M. C. Chhantbar ,H. H. Joshi, Study of infrared spectroscopy and elastic properties of fine and coarse grained nickel-cadmium ferrites, $\mathrm{J}$ Mater Sci 41:7308-7318 (2006).

44. S. A. Shaker, H. Khaledi, S. Cheah, H. M. Ali, New Mn(II), Ni(II), Cd(II), Pb(II) complexes with2-methylbenzimidazole and other ligands.Synthesis, spectroscopic characterization, crystalstructure, magnetic susceptibility and biologicalactivity studies, Arabian journal of chemistry, 9 S1943-S1950 (2016)

45. M. M. Rashad, A. Khalifa, D. A. Rayan, M. G. Fayed, Superparamagnetic $\mathrm{Cu}^{2+}$ substituted $\mathrm{Mn}-\mathrm{MgFe}_{2} \mathrm{O}_{4}$ powders prepared through co-precipitation strategy: structural, microstructure and magnetic properties, Journal of Materials Science: Materials in Electronics 29:3391-3400 (2018).

46. B. G Toksha, S. E. Shirsath, S. M. Patange, Structural investigations and magnetic properties of cobalt ferrite nanoparticles prepared by sol-gel auto combustion method. Solid state commun. 147:479-483 (2008).

47. R. C. Kambale, P. A. Shaikh, C. H. Bhosale, The effect of Mn substitution on the magnetic and dielectric properties of cobalt ferrite synthesized by an auto combustion route. Smart Mater Struct. 18:115028-115037 (2009).

48. H. Dubey and P. Lahiri, Synthesis, structural, dielectric and magnetic properties of $\mathrm{Cd}^{2+}$ based Mn nanosized ferrites, MATERIALS TECHNOLOGY 36 131-144 (2021). 
49. Manal Mahdy, Inas El-Zaway, Gamal Turky, Lead Telluride Nano-crystalline Thin Films: A Broadband Dielectric Spectroscopy Study. Current Applied Physics 19 787-793 (2019).

50. H. abu Mustafa, G. M. El-Komy, G. M. Turky, Microstructure and Dielectric study of Pure BST and doped BSTF ceramic materials by broadband dielectric spectroscopy, Current Applied Physics 20 611-618 (2020).

51. M. Fayad, M. Abdel-Baki, EM Hamzawy, Gamal M. Turky, Gehan T. El-Bassyouni, Influence of $\mathrm{CuO}$ on crystallization and electrical properties of $\mathrm{B}_{2} \mathrm{O}_{3}-\mathrm{Bi}_{2} \mathrm{O} 3-\mathrm{GeO}_{2}-\mathrm{CaF}_{2}$ glass system for optoelectronic application. Journal of Non-Crystalline Solids 544 (2020) 120185.

52. A.S. Abouhaswa, Y.S. Rammah, Gamal M. Turky, Characterization of zinc lead-borate glasses doped with Fe3+: Optical, dielectric and ac-conductivity investigations. Journal of Materials Science: Materials in Electronics 31 17044-17054 (2020).

53. A.K. Jonscher, The universal dielectric response, Nature 267 673-679 (1977).

54. A. A. Azab, A. M. Mansour, G. M. Turky, Structural, Magnetic, and Dielectric properties of $\mathrm{Sr}_{4} \mathrm{Fe}_{6} \mathrm{O}_{13}$ ferrite prepared of small crystallites, Scientific Reports | 10:4955 (2020).

55. Sh. Sh. Omara, G. Turky, A. Ghoneim, A. F. Thünemann, M. H. Abdel Rehim and A. Schönhals," Hyperbranched poly(amidoamine)/kaolinite nanocomposites:Structure and charge carrier dynamics " Polymer 121 64-74 (2017) 
Figures

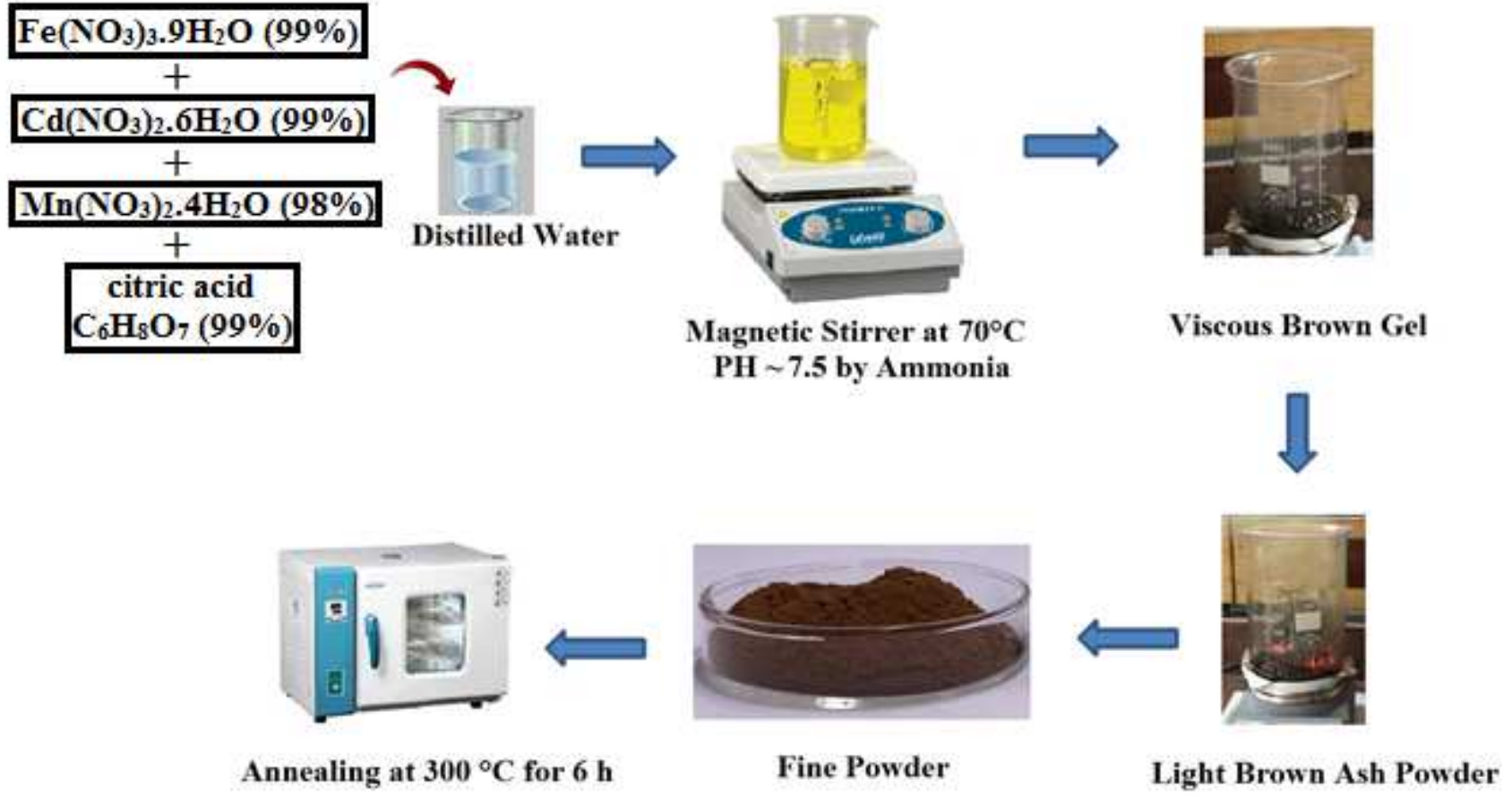

\section{Figure 1}

Flow chart of Flash auto-combustion method for prepared Cd1-xMnxFe2O4 ferrite samples. 


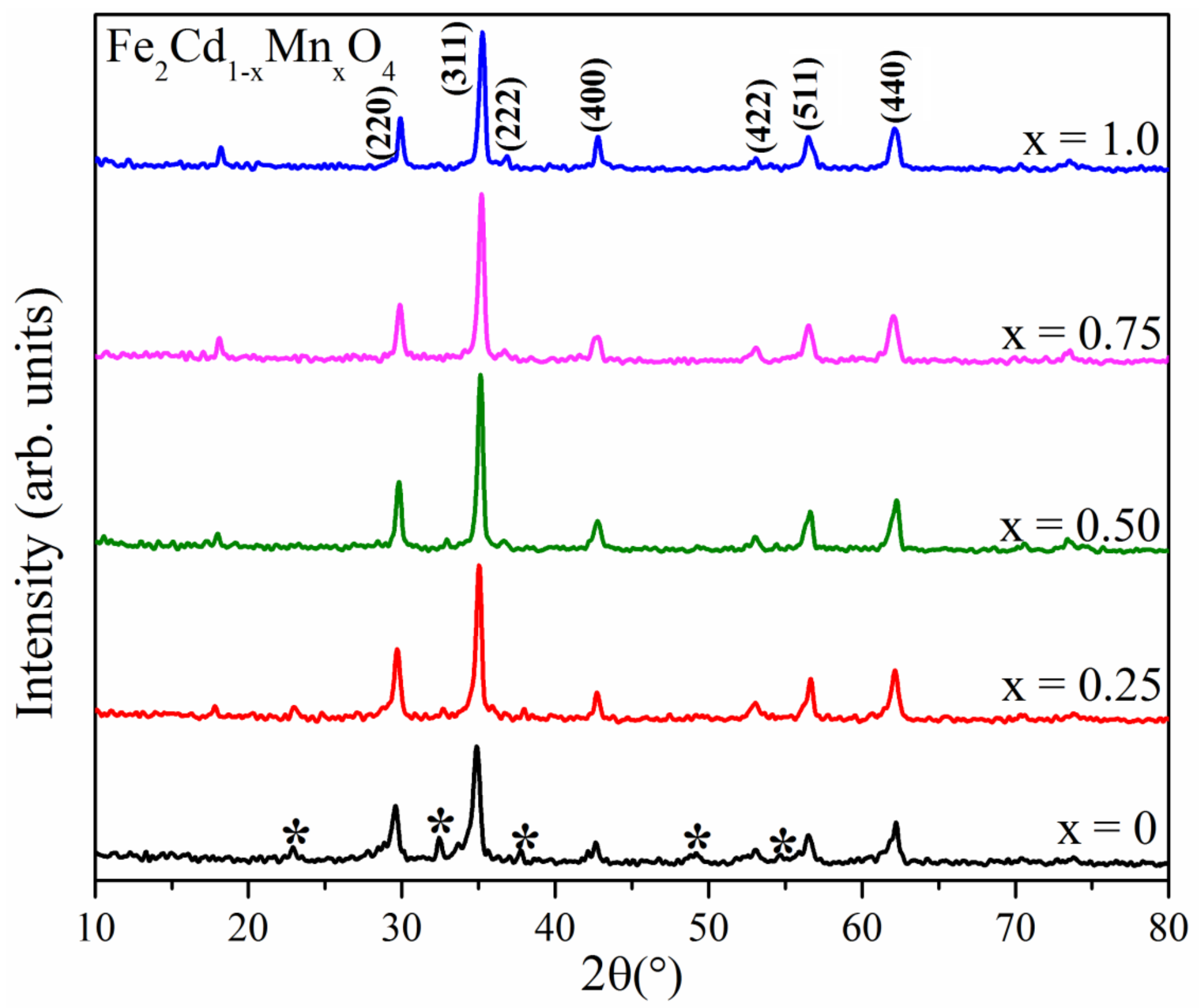

Figure 2

X-ray diffraction patterns of the prepared samples Cd1-xMnxFe204. The peaks associated with a-Fe2O3 impurity phase are marked with asterisks. 

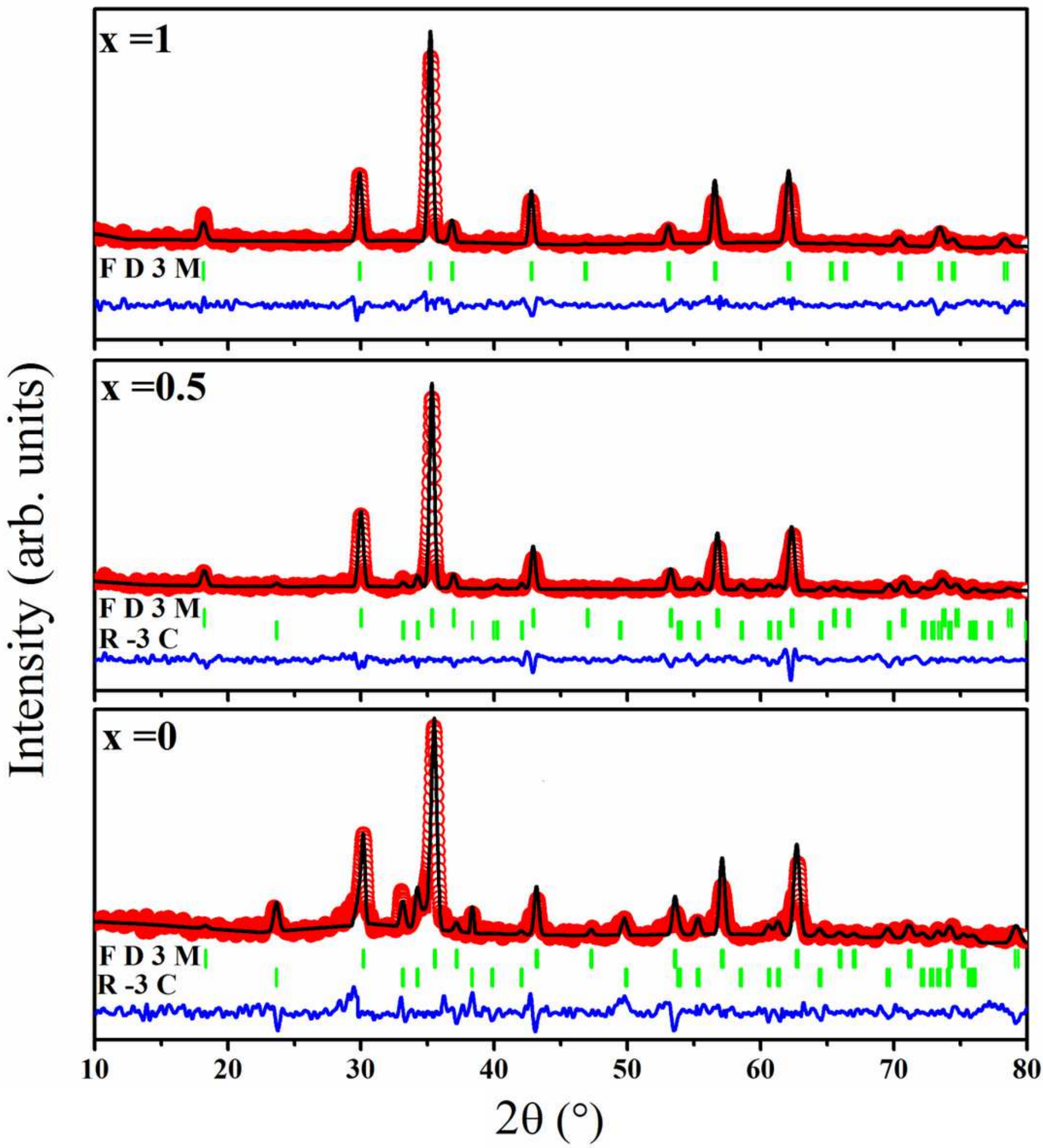

Figure 3

Observed (symbols) and calculated (line) patterns for the samples $x=0,0.5$, and 1 . Vertical bars indicate positions of Bragg reflection for the existing phases. The difference between calculated and observed intensities is shown in the bottom. 
(a)
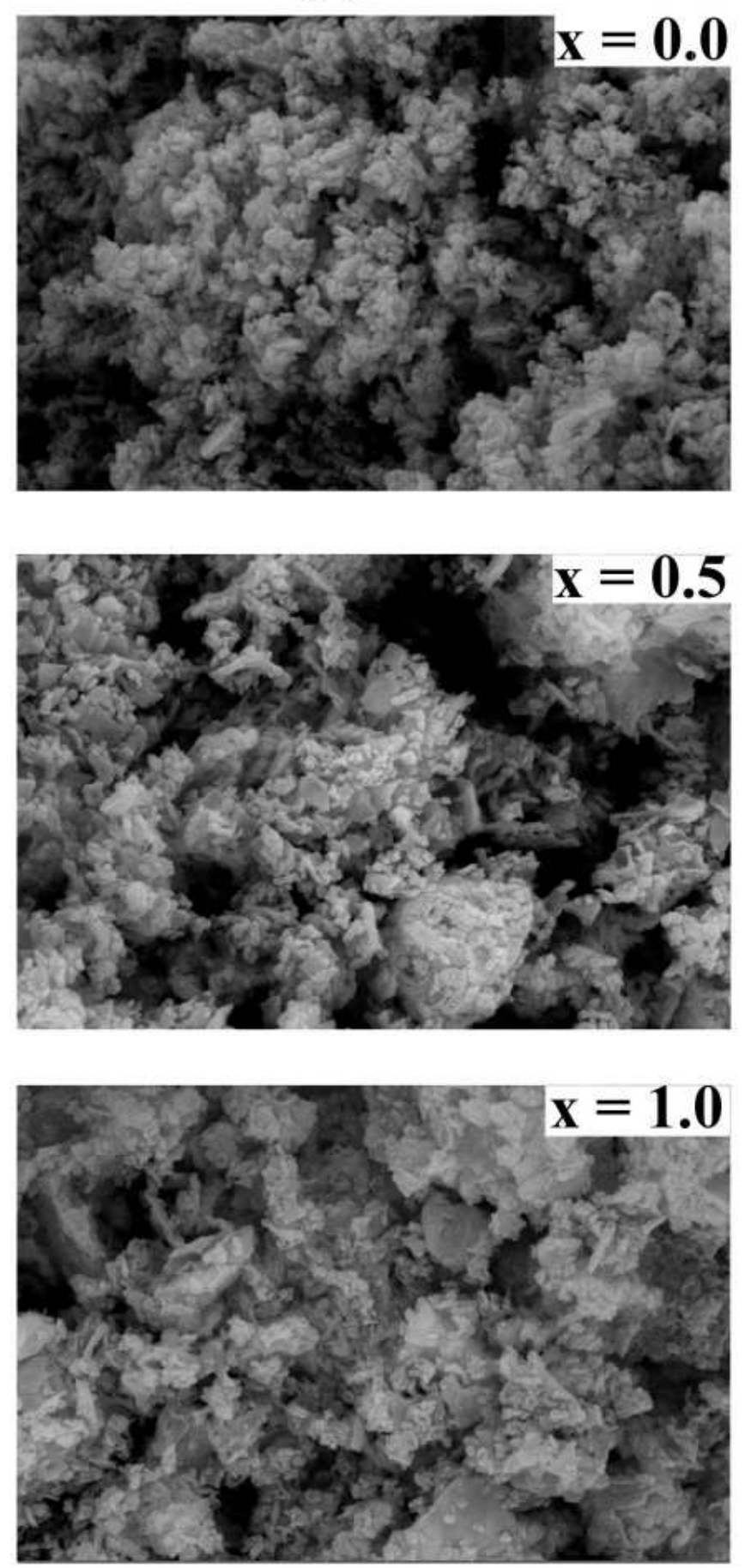

(b)
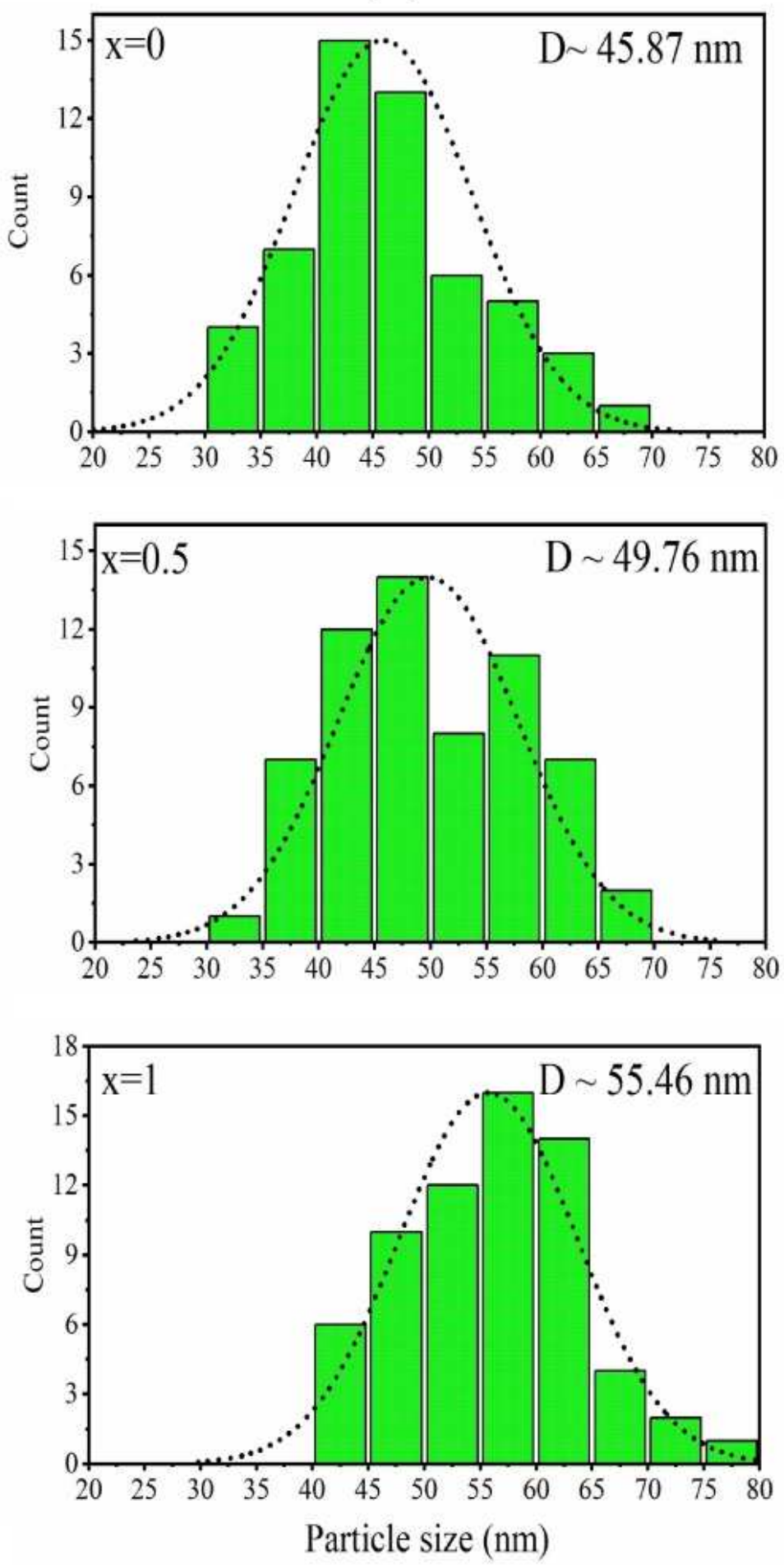

Figure 4

(a) SEM images of prepared samples with $x=0,0.5$ and 1 (b) distribution of particles in size by using Image $\mathrm{J}$ software. 


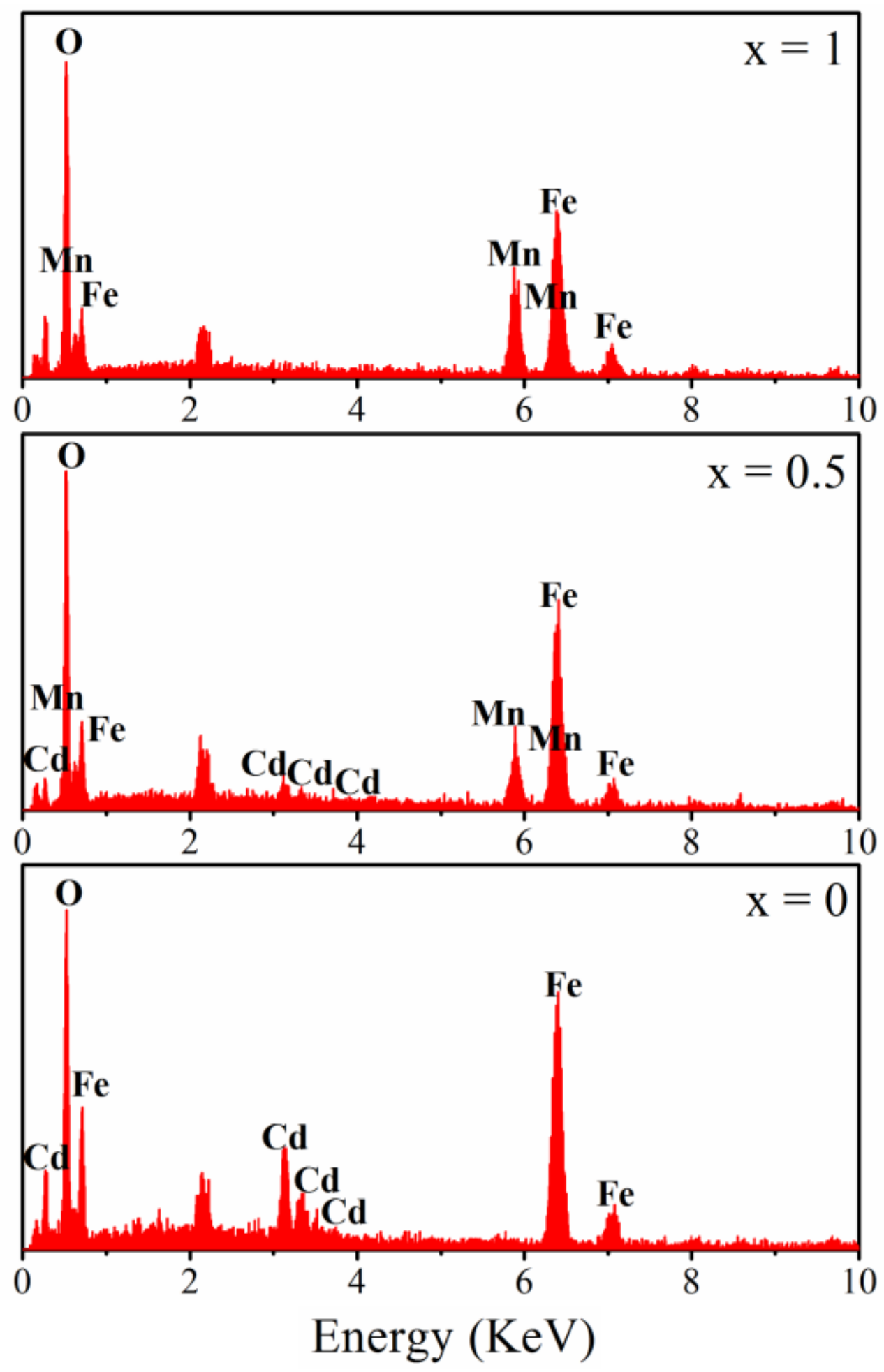

Figure 5

EDX pattern of MnxCd1-x Fe2O4 ( $x=0,0.5$ and 1.0) samples 


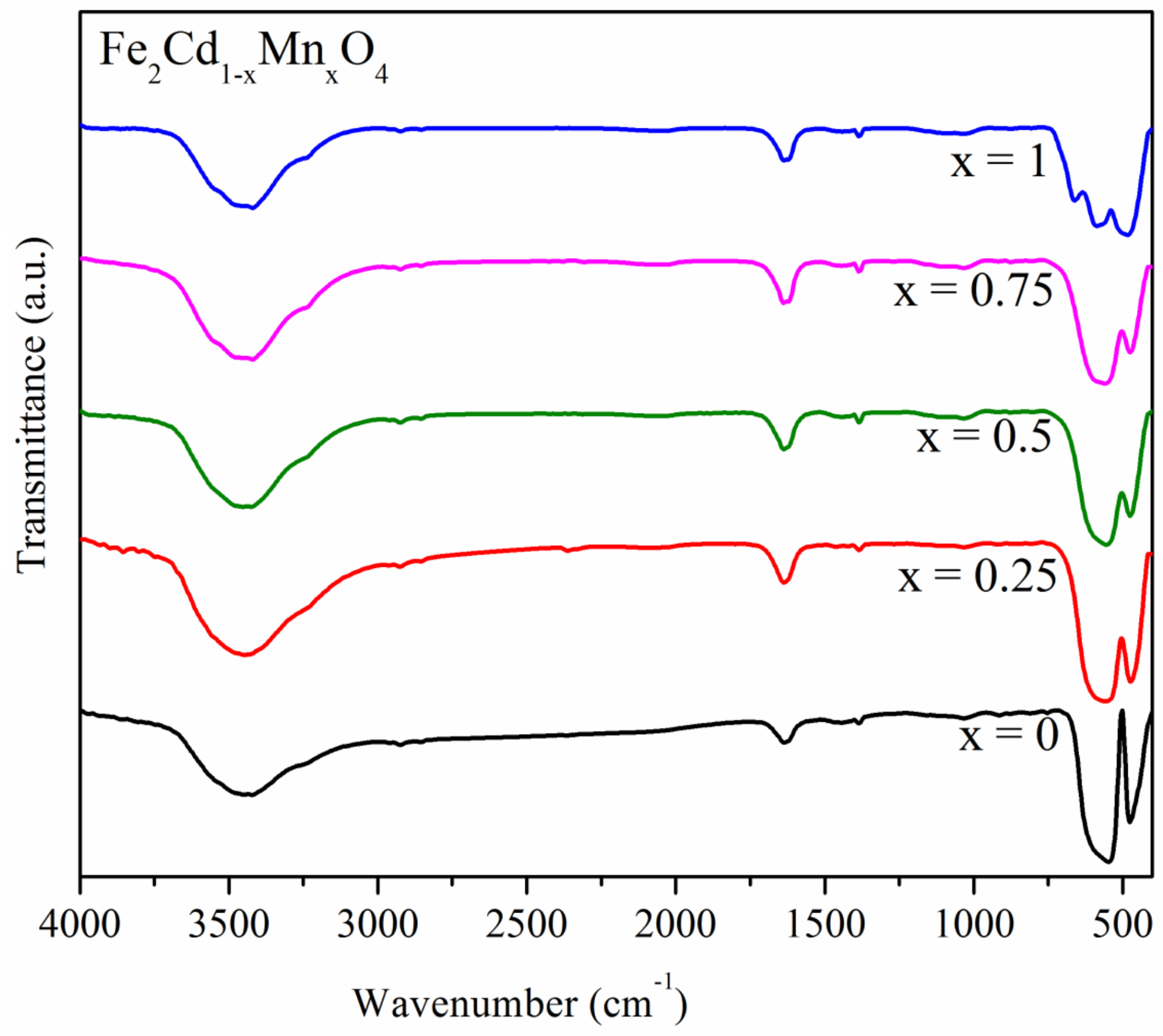

Figure 6

Fourier-Transform Infrared spectroscopy (FTIR) measurements of Cd1-xMnxFe204 nanoparticles in the range $400-4000 \mathrm{~cm}-1$ 


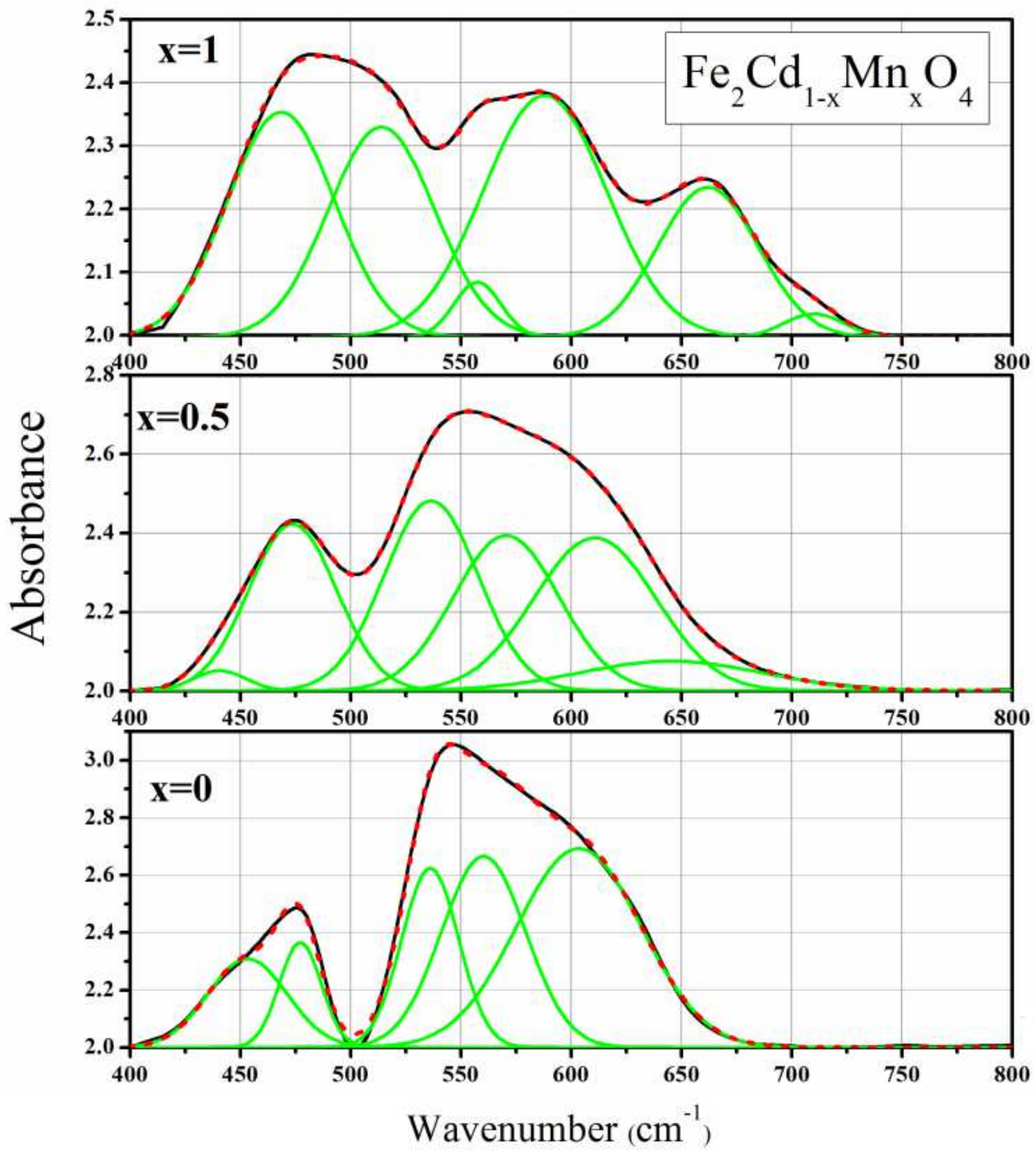

Figure 7

Band deconvolution of the IR spectrum for $x=0,0.5,1$ samples in the range $400-800 \mathrm{~cm}-1$ 


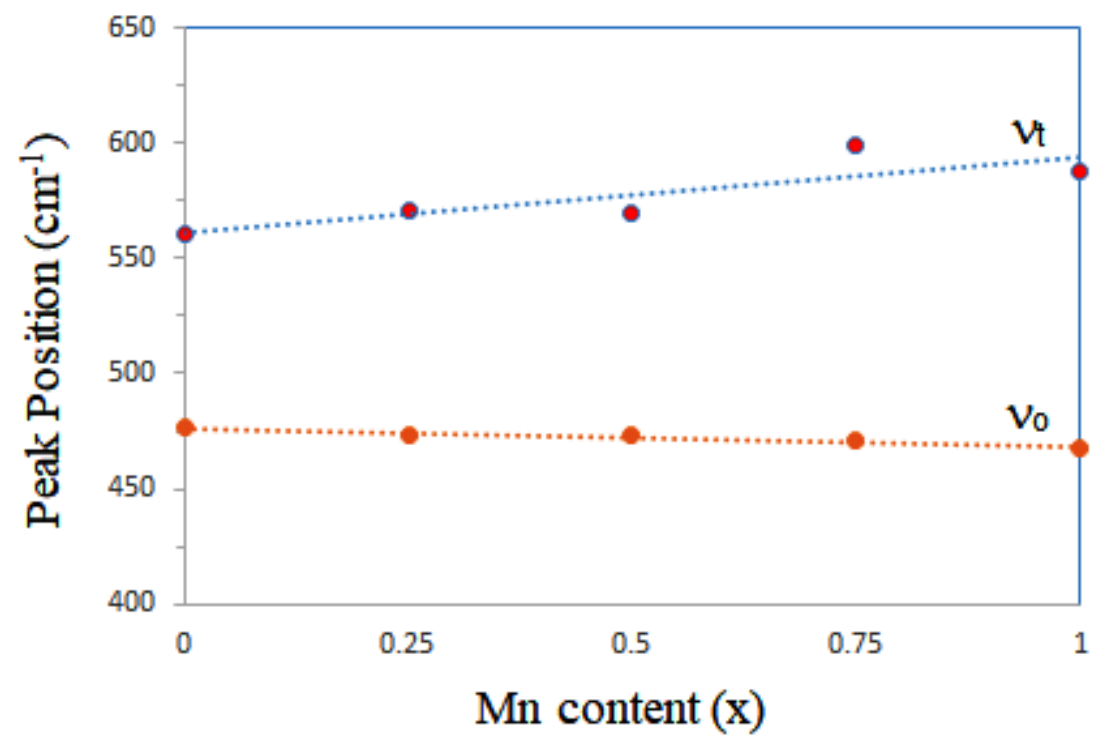

Figure 8

Variation of tetrahedral $(\nabla t)$ and octahedral $(\llbracket 0)$ stretching vibrations of metal ion and oxygen complex with Mn-content (x)

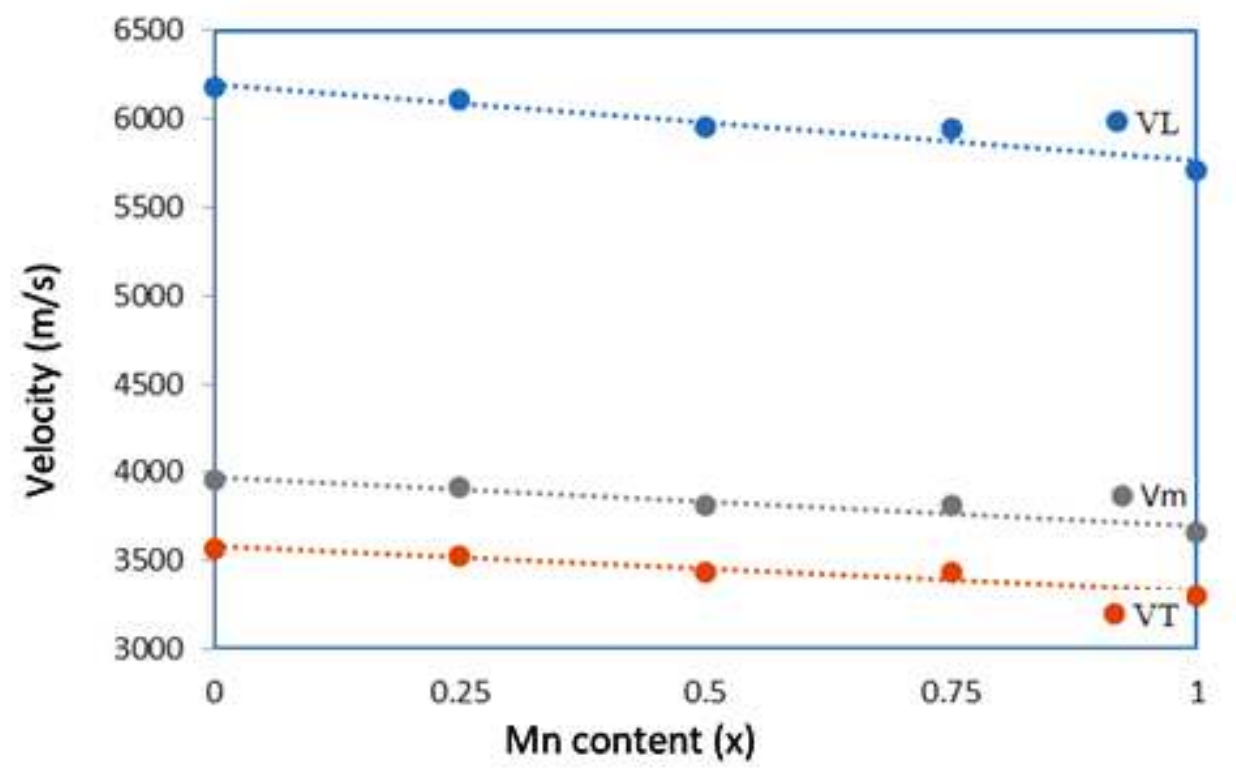

\section{Figure 9}

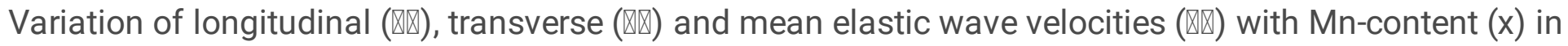
Cd1-x MnxFe2O4. 


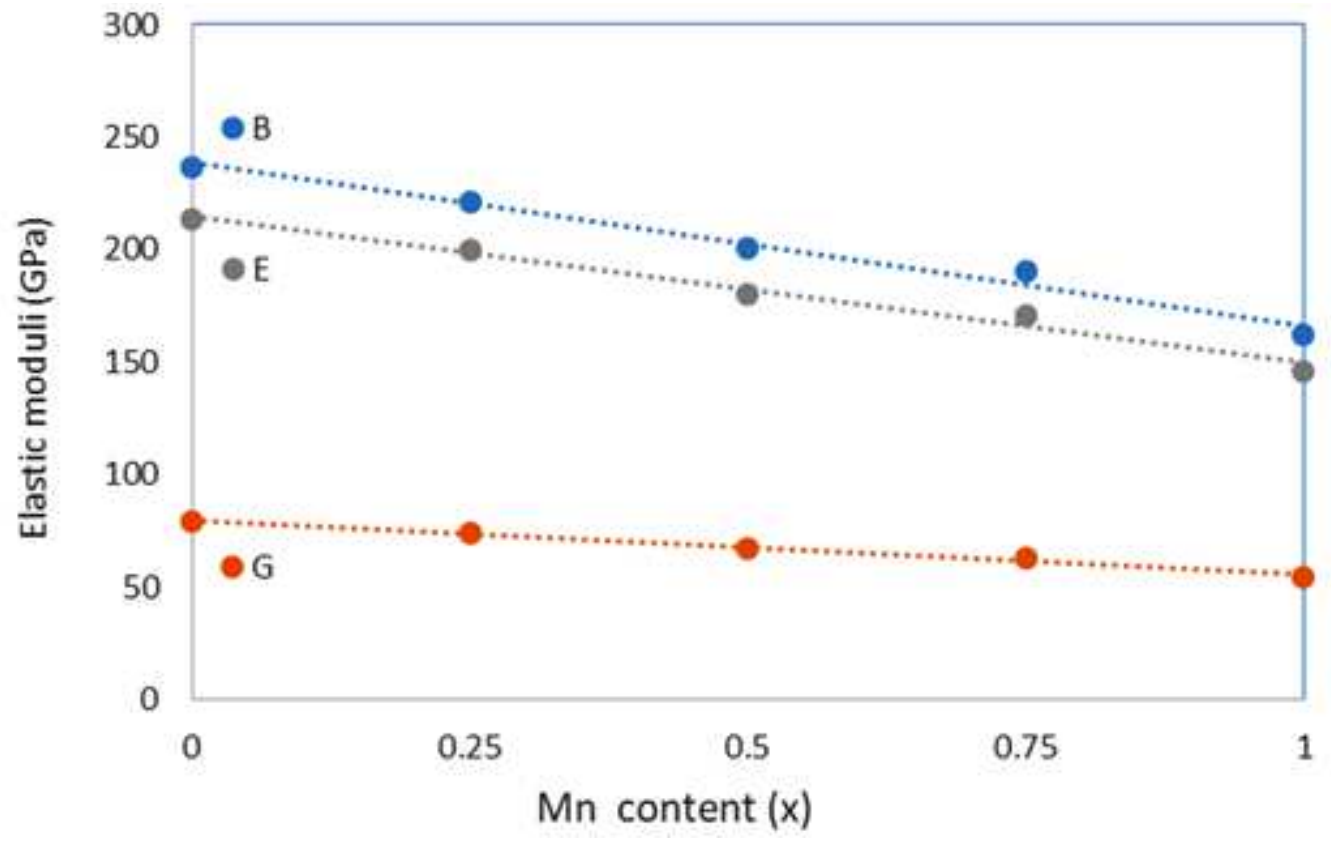

Figure 10

Variation of bulk modulus (B), rigidity modulus(G), Young modulus (E) with Mn-content (x) in Cd1xMnxFe204 ferrites 


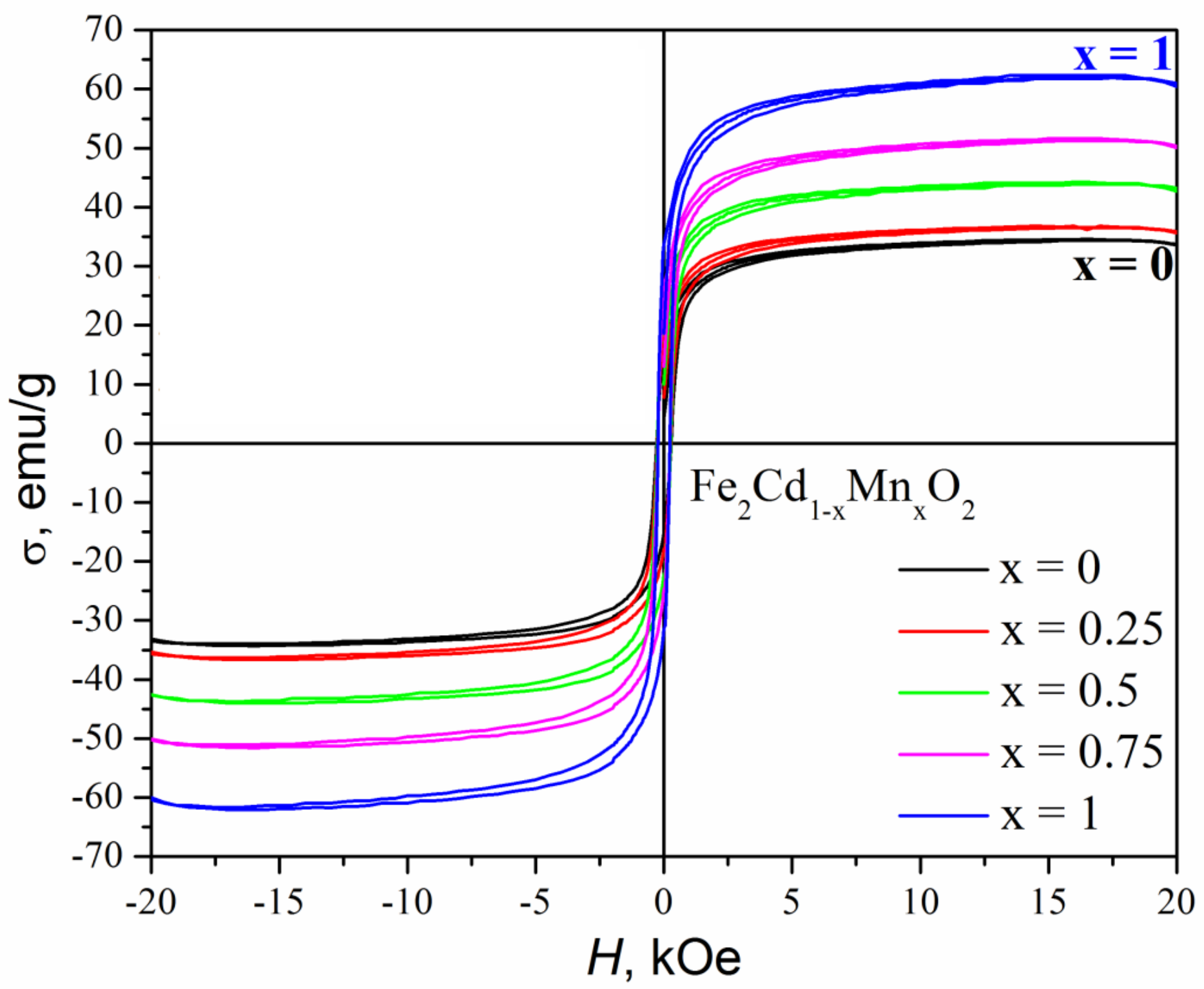

Figure 11

M-H hysteresis loops of the prepared Cd1-xMnxFe2O4 ferrites. 


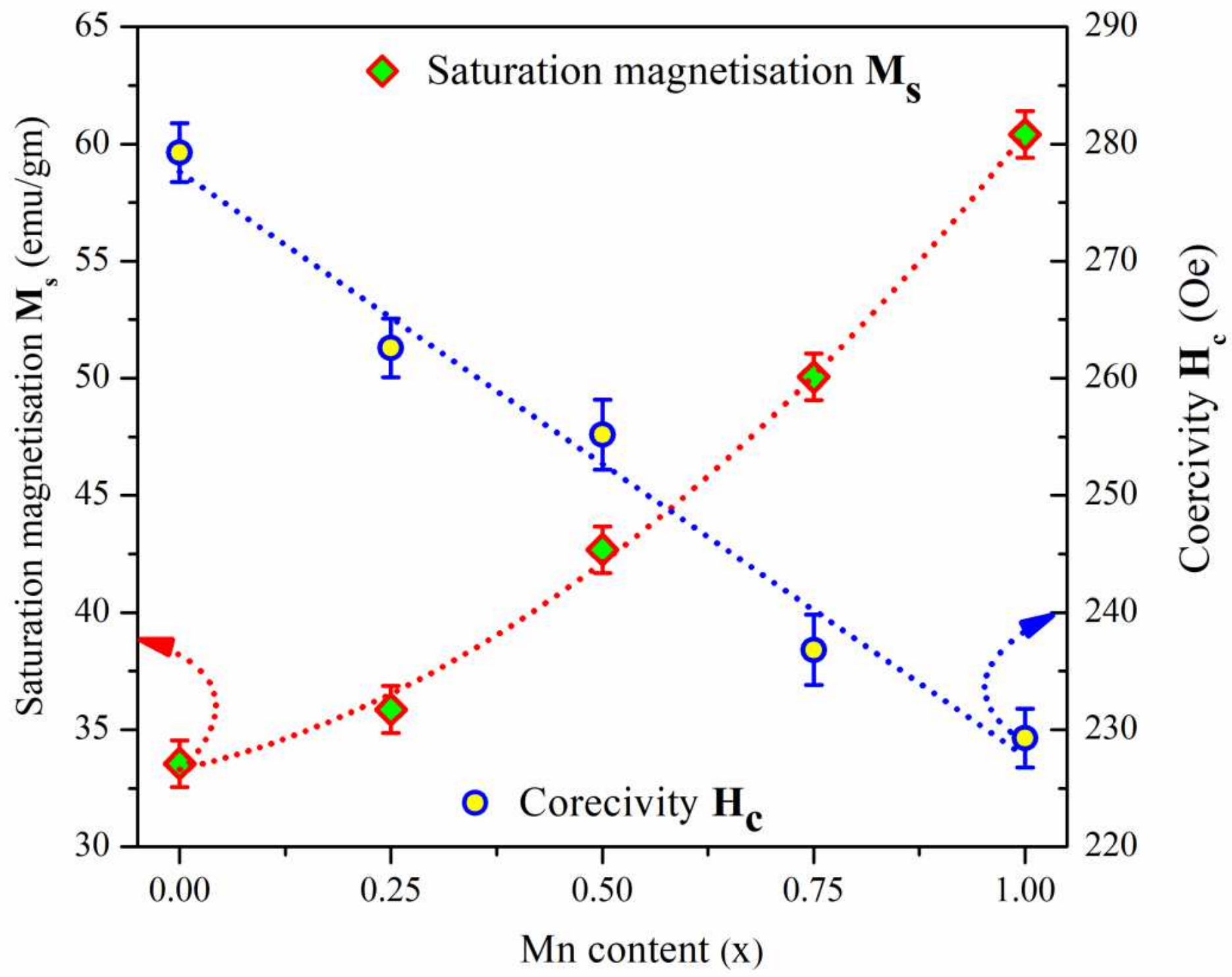

Figure 12

Saturation magnetization (Ms) and coercivity $(\mathrm{Hc})$ as a function of Mn-content. 


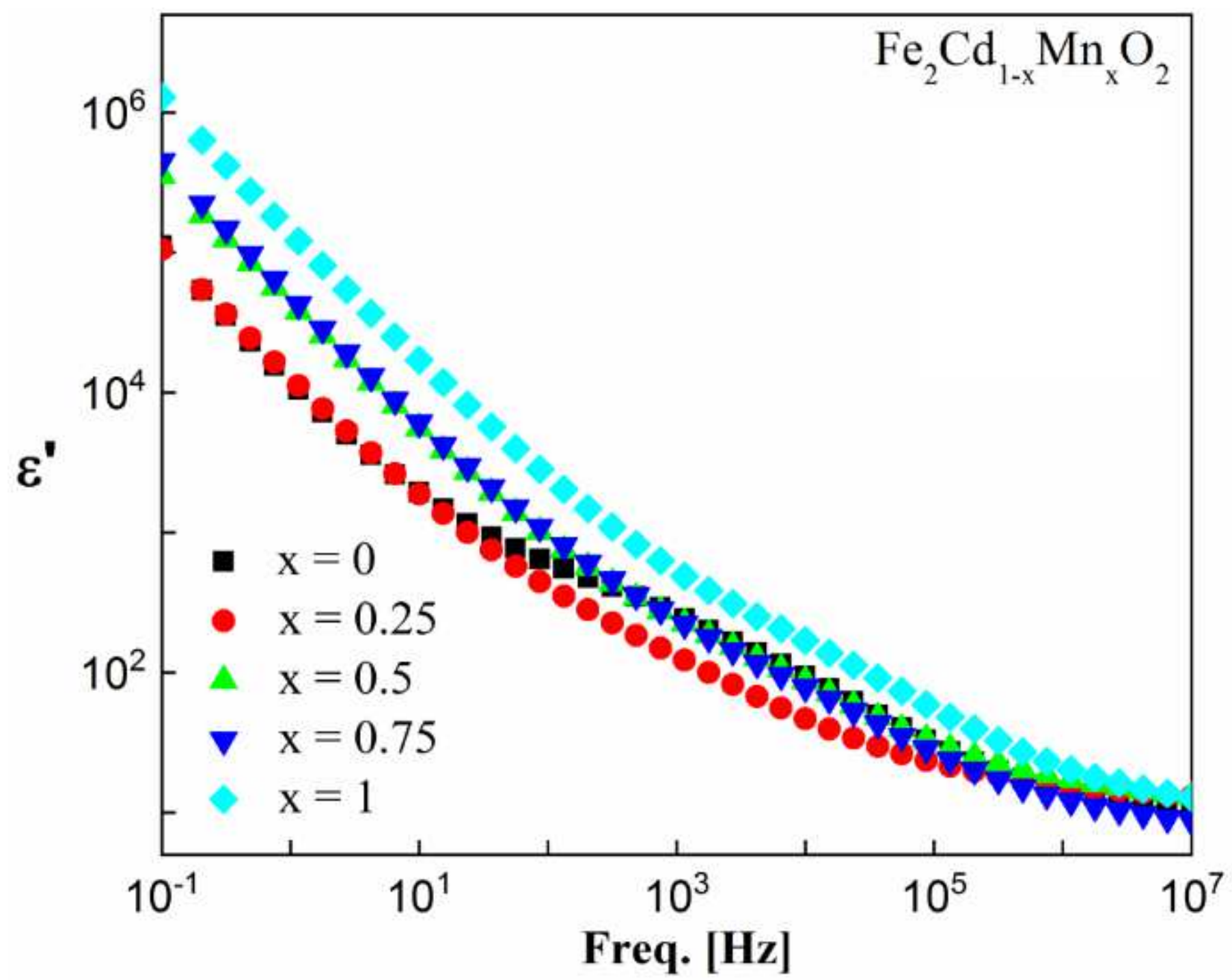

Figure 13

Permittivity, $\sigma^{\prime}$, versus frequency for the as-prepared Cd1-x MnxFe204 ferrites measured at room temperature. 


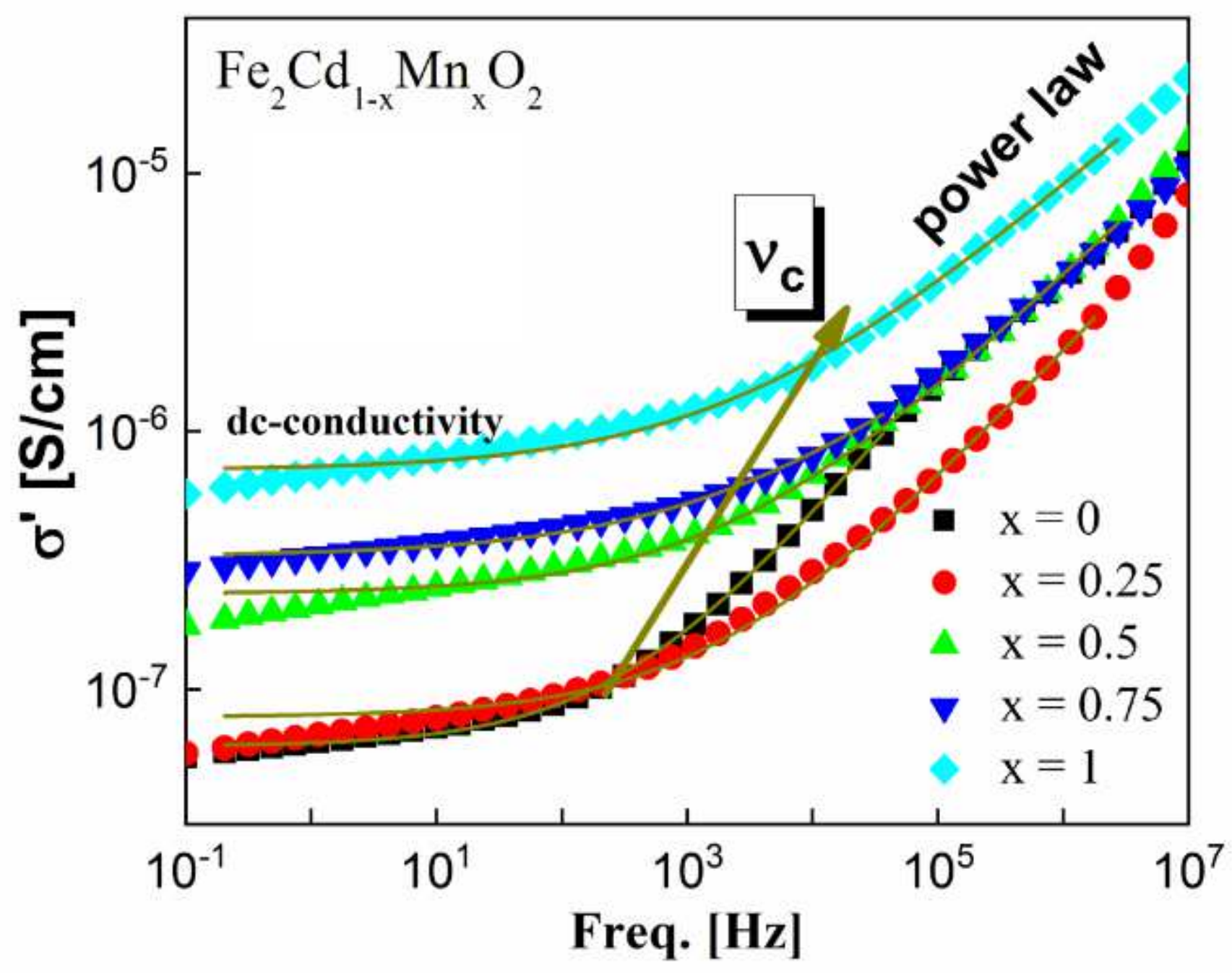

Figure 14

The real part of conductivity, $\sigma^{\prime}$, versus frequency for as-prepared Cd1-x MnxFe204 ferrites measured at room temperature. The solid lines are the fitting of Eqn. III to the data. 


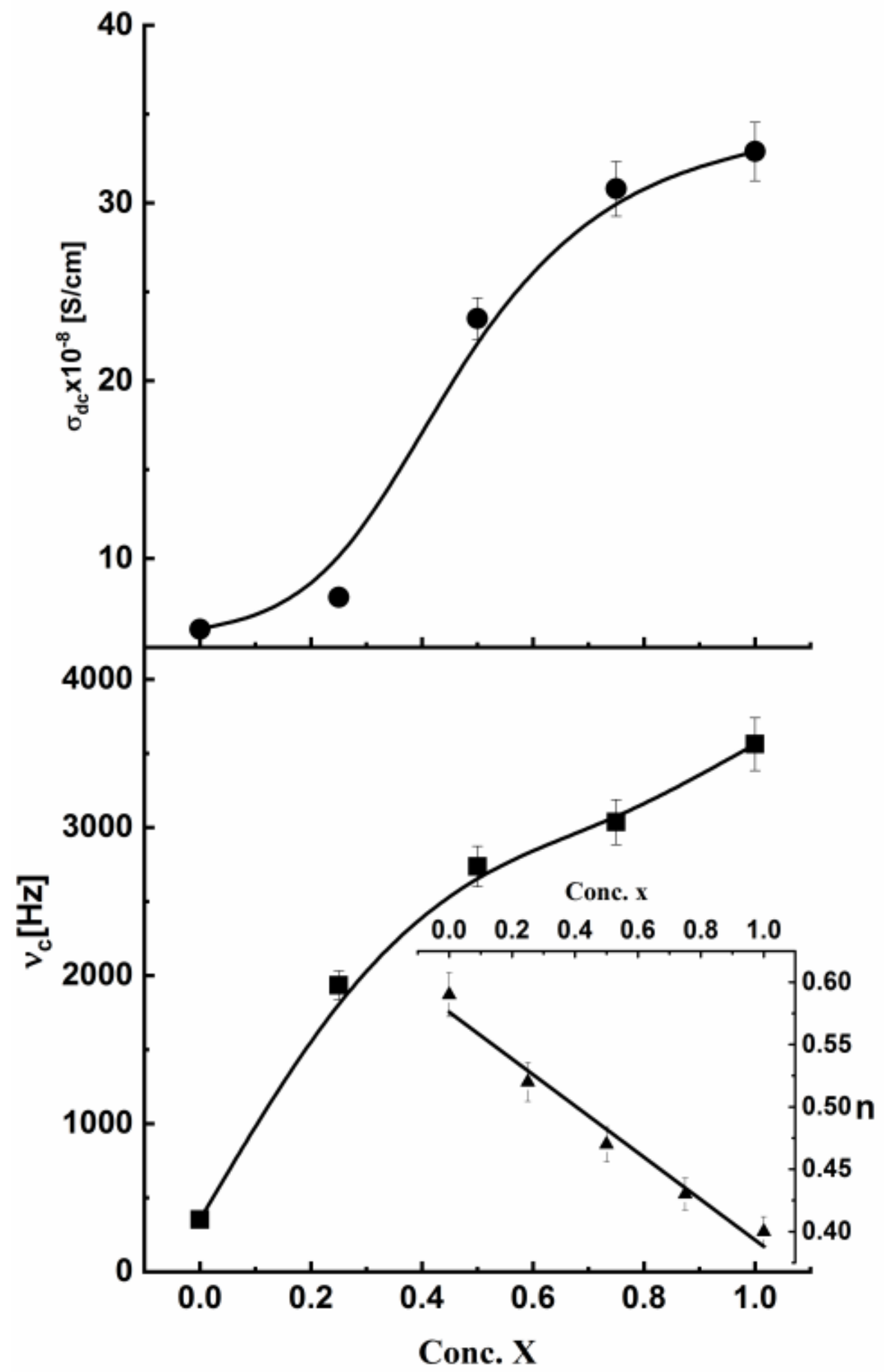

Figure 15

The two main fit parameters of Eqn. III, odc and vc, as a function of Mn concentration. Solid lines are just guides for eyes. The inset shows the exponential parameter $n$ against concentration. Solid line is a linear fit to the data

\section{Supplementary Files}


This is a list of supplementary files associated with this preprint. Click to download.

- ListofTables.pdf 